\title{
A Water Cycle-based Error Minimization Technique in Predicting Bearing Capacity of Foundation
}

Hossein Moayedi

Ton Duc Thang University

Amir Mosavi ( $\square$ amir.mosavi@kvk.uni-obuda.hu )

Ton Duc Thang University

\section{Research Article}

Keywords: Bearing capacity, Settlement measurement, Artificial neural network, Water cycle algorithm

Posted Date: February 17th, 2021

DOl: https://doi.org/10.21203/rs.3.rs-251756/v1

License: (c) (i) This work is licensed under a Creative Commons Attribution 4.0 International License. Read Full License 


\title{
A Water Cycle-based Error Minimization Technique in Predicting Bearing Capacity of Foundation
}

\section{Hossein Moayedi, Amir Mosavi}

Atmospheric Science and Climate Change Research Group, Ton Duc Thang University, Vietnam amir.mosavi@kvk.uni-obuda.hu

\begin{abstract}
Selecting the appropriate training technique is a significant step in utilizing intelligent approaches. It becomes even more important when it comes to critical problems like analyzing the bearing capacity of foundations. This study investigates the feasibility of a capable metaheuristic algorithm, called water cycle algorithm (WCA), for training a multi-layer perceptron (MLP). The WCA-MLP is applied to a large finite element dataset to predict the settlement. The results of this model are compared with electromagnetic field optimization (EFO) and shuffled complex evolution (SCE) benchmarks. With reference to the obtained Pearson correlation factors (larger than 0.88 in all stages), all employed models are suitable for the mentioned objective. Moreover, it was observed that the training error of the WCA was 5.84 and 3.89\% smaller than the EFO and SCE, respectively. Likewise, the accuracy of the WCA-MLP was 1.85 and 2.04\% larger in the testing phase. Also, a predictive equation is finally elicited for practical applications in compatible circumstances.
\end{abstract}

Keywords: Bearing capacity; Settlement measurement; Artificial neural network; Water cycle algorithm.

\section{Introduction}

With recent advances in computational intelligence, many scholars have replaced traditional methods with economical and accurate machine learning, deep learning [1-7], decision making [8; 9], and artificial intelligence-based tools [10-14]. These novel approximation techniques are well employed in various engineering field such as in evaluating the environmental concerns [15-25], implications for natural environmental [26-34], water resources management [35-41], energy efficiency [42-50], structural design [51-61], image processing [62-65], feature selection/extraction [66-70], face recognition [71-74], control performance [75], vibration analysis [76], climate change [77], managing the smart cities [78], project management [79], while in the field of medical science artificial intelligence employed to have a better diagnosis of a particular patients [80-84], early diagnosis of 
them [85; 86], or medical image classification [87]. There have been many novel algorithms enhancing the current predictive neural network-based models. Metaheuristic algorithms have been highly regarded in various problems that demand an optimal solution [85]. The hybrid optimization techniques such as differential evolution [88], data-driven robust optimization [89], whale optimization algorithm [90; 91], harris hawks optimization [88; 92], differential edge detection algorithm [93], many-objective sizing optimization [94], fruit fly optimization [95], moth-flame optimization strategy [96; 97], bacterial foraging optimization [98], ant colony optimization [99], particle swarm optimization (PSO) [100-102], chaos enhanced grey wolf optimization [82], and quantum-enhanced multiobjective large-scale [103].

The efficient determination of ultimate bearing capacity $(\mathrm{BC})$ of foundations is a significant consideration in designing various structures [104-106]. Khorrami et al. [107] presented an explicit formulation for ultimate BC for foundations settled on granular soil through an M5' model tree. As an advantage, the proposed model showed lower uncertainty as well as larger efficiency in comparison with a number of conventional theories. Likewise, Khorrami and Derakhshani [108] used a hybrid of this model coupled with genetic programming for calculating the $\mathrm{BC}$ for a system of footing and cohesionless soil. Sethy et al. [109] introduced adaptive neuro-fuzzy inference system (ANFIS) as a capable approximator for computing the $\mathrm{BC}$ of rectangular footing with eccentrically loading. Also, in comparison with artificial neural network (ANN), the output pattern of the ANFIS was in a larger agreement with the expected one (the coefficients of determination of 0.9024 vs. 0.9118). The competency of support vector machine (SVM) and random forest for estimating the BC of footings placed on rocks was demonstrated by Dutta et al. [110]. Moayedi and Hayati [111] tested several soft computing approaches for exploring the BC of shallow foundations installed near homogeneous slopes. The findings revealed the excellence of the feedforward ANN compared to models like tree regression fitting and SVM. In a similar effort, Acharyya and Dey [112] investigated the feasibility of the ANN. They also analyzed the importance of effective factors using this model and found that the angle of internal friction plays the most influential role. Aouadj and Bouafia [113] embedded a new mathematical activation function and fed the proposed network by the records of the cone penetration test. Large agreements between the desired and produced outputs, as well as around 30\% higher accuracy compared to classical approaches, demonstrated the suitability of the proposed model. More applications of the ANNs for this objective can be found in many earlier studies [114-116].

It is well accepted that diverse optimization theories and algorithms can overcome the difficulties that come up with intricate problems [89; 117-127]. Genetic algorithm (GA) is a popular optimization method which was applied by Hamrouni et al. [128] for probabilistic analysis of seismic BC. Saha et 
al. [129] presented a solution to the ultimate BC problem using symbiosis organisms search. Confirmed by numerical analysis (in the PLAXIS environment), the acceptability of the proposed method was shown for future applications. Jin et al. [130] could accurately study the ultimate BC and critical slip surface of a rough embedded foundation placed on sands using improved radial movement optimization (IRMO). The efficiency of biogeography-based optimization algorithm (BBO), evolution strategy (ES), and differential algorithm (DE) was investigated by Kashani et al. [131] for the optimal design of the foundation. Gandomi and Kashani [132] professed the superiority of teaching-learning-based optimization algorithm (TLBO) over various swarm-based strategies, such as accelerated PSO, WOA, MFO, for the economical design of shallow foundations.

Moayedi et al. [133] compared two highly popular optimizers of imperialist competition algorithm (ICA) and particle swarm optimization (PSO) for enhancing the performance of the ANN applied to bearing capacity estimation of shallow circular footing. The outputs of the ANNs developed by the PSO and ICA achieved the $\mathrm{R}^{2}$ values of 0.9575 and 0.9467 , respectively. Therefore, they concluded the excellence of the PSO-ANN model. A comparison between four metaheuristic strategies of ant colony optimization (ACO), league champion optimization (LCA), whale optimization algorithm (WOA), and moth-flame optimization (MFO) incorporated with ANN in forecasting the stability/failure of a soil-footing system was conducted by Moayedi et al. [134]. Respective accuracies of 94.4, 93.5, 93.9, and 93.9\% showed the larger optimization competency of the ACO algorithm.

The literature addresses the wide application of metaheuristic algorithms in the BC calculation [135; 136]. It has been well concluded that these algorithms can efficiently deal with providing optimal solutions, due to their global search capability. Based on the findings of earlier studies concerning the successful use of newly-designed techniques, this study uses water cycle algorithm (WCA) for training an ANN in the BC analysis. The WCA is a robust search strategy that has been broadly employed for different applications [137; 138]. Moreover, the competency of this model is checked by two benchmark techniques, namely electromagnetic field optimization (EFO) and shuffled complex evolution (SCE) which are known as relatively quicker algorithms. This strategy, i.e., utilizing automatic error minimization techniques as the trainer of $\mathrm{ANN}$, has been regarded as a promising solution for complex engineering issues.

\section{Methodology}

\subsection{The WCA technique}

Most metaheuristic algorithms are nature-inspired, meaning that the main idea is elicited from the natural phenomena or the behavior of creatures. The WCA, as is implied by the name, mimicks the way rivers and streams end up with the sea [139]. Melted snow and glaciers flow downhill to form a stream (or a river). Their water is evaporated, becomes clouds, and returns to the earth [140]. 
The steps required for implementing the WCA can be explained as follows:

- Step1: Setting the parameters of the algorithm including $K_{s r}, K_{\text {pop }}, d_{\max }, I t_{\max }$.

- Step1: Scattering the initial population and determining sea, streams, and rivers. Assuming $K_{\text {pop }}$ as the total size of the population, $K_{s r}=1+$ Number of rivers, and $K_{\text {streams }}\left(=K_{p o p}\right.$ $K_{s r}$ ) as the number of streams, this process is expressed by the below equation:

Total population $=\left[\begin{array}{c}\text { Sea } \\ \text { River }_{1} \\ \vdots \\ \text { Stream }_{K_{s r+1}} \\ \vdots \\ \text { Stream }_{K_{p o p}}\end{array}\right]=\left[\begin{array}{cccc}x_{1}^{1} & x_{2}^{1} & \ldots & x_{K}^{1} \\ x_{1}^{2} & x_{2}^{2} & \ldots & x_{K}^{2} \\ \vdots & \vdots & \vdots & \vdots \\ x_{1}^{K_{p o p}} & x_{2}^{K_{p o p}} & \ldots & x_{K}^{K_{p o p}}\end{array}\right]$

where river, stream, and the sea represent a particular solution by a $1 \times \mathrm{K}$-dimensional array as $\left[x_{1}, x_{2}, \ldots, x_{K}\right]$.

- Step 3: The cost of each member of the existing population is reflected as follows:

$C_{j}=\operatorname{Cost}_{j}=f\left(x_{1}^{j}, x_{1}^{j}, \ldots, x_{K}^{j}\right) \quad j=1,2, \ldots, K_{p o p}$

- Step 4: Given $N S_{k}$ as the number of streams discharging in the corresponding rivers or the sea, Equation 3 and 4 give the flow intensity of sea and rivers:

$C_{k}=\operatorname{Cost}_{k}-C F_{K_{s r+1}} \quad k=1,2, \ldots, K_{s r}$

$N S_{k}=$ round $\left\{\left|\frac{C_{k}}{\sum_{k=1}^{K_{S r} r} C_{k}}\right| \times K_{\text {Streams }}\right\}, \quad k=1,2, \ldots, K_{s r}$

- Step 5: Below relationships describe the streams flowing into the sea and rivers:

$X_{\text {stream }}(t+1)=X_{\text {stream }}(t)+\operatorname{rand}(0,1) \times G \times\left(X_{\text {sea }}(t)-X_{\text {stream }}(t)\right)$

$X_{\text {stream }}(t+1)=X_{\text {stream }}(t)+\operatorname{rand}(0,1) \times G \times\left(X_{\text {river }}(t)-X_{\text {stream }}(t)\right)$

where $G$ is a number varying from 1 and 2 (close to 2). Notably, the streams are allowed to move to the rivers from different directions once $C>1$.

- Step 6: The movement of the rivers toward downhill (or the sea) can be formulated as follows:

$X_{\text {river }}(t+1)=X_{\text {river }}(t)+$ rand $\times G \times\left(X_{\text {sea }}(t)-X_{\text {river }}(t)\right)$

- Step 7: The position of a stream that gives a better-fitted solution replaces that of the river.

- Step 8: Likewise, the position of a river which gives a better-fitted solution replaces that of the sea. 
- Step 9: Given $d_{\max }$ as a very small value for controlling the intensification level, $\mathrm{B}_{\mathrm{U}}$ and $\mathrm{B}_{\mathrm{L}}$ as the upper and lower bound, respectively, the following procedure checks the conditions of evaporation (for unconstrained problems):

If $\left|X_{\text {sea }}-X_{\text {river }}^{j}\right|<d_{\text {max }}$ or rand $<0.1 \quad j=1,2, \ldots, K_{\text {sr }}-1$

Rain based on Equation 9

End if

$X_{\text {stream }}^{\text {new }}(t+1)=B_{L}+$ rand $\times\left(B_{U}-B_{L}\right)$

As for constrained problems, the WCA uses the below code for enhancing its capability:

If $\left|X_{\text {sea }}-X_{\text {stream }}^{j}\right|<d_{\text {max }} \quad j=1,2, \ldots, N S_{k}$

Rain based on Equation 11

End if

$X_{\text {stream }}^{\text {new }}(t+1)=X_{\text {sea }}+\sqrt{\delta} \times \operatorname{randn}(1, K)$

where randn is a random number and $\delta$ signifies the variance term showing the searching region in the vicinity of the sea. This is worth noting that for preventing premature convergence in such problems, Equation 10 is only implemented for the streams which have direct movements toward the sea.

- Step 10: The $d_{\max }$ is decreased as follows:

$d_{\max }(t+1)=d_{\max }(t)-\frac{d_{\max }(t)}{I t_{\max }}$

- Step 11: The algorithm is finished if any stopping criterion is met, otherwise it repeats the process from step $5[141 ; 142]$.

\subsection{Benchmark optimizer}

Electromagnetic field optimization, as the name indicates, is inspired by the electromagnetic behavior of different poles. In this regard, electromagnets with similar/dissimilar poles repel/attract each other. This algorithm was suggested by Abedinpourshotorban et al. [143]. The individuals of the EFO are electromagnetic particles. The goodness of each particle is the basis of classifying them into three groups by the name positive field, negative field, and neutral field. The main idea of this technique for improving the solutions is generating and replacing new particles. More clearly, the generated particle with a better fitness magnitude replaces the worst one. For generating a new individual, one particle is randomly chosen from each one of the triple fields. The position and the pole of the neutral particle are first given to the produced individual. The positive and negative electromagnetics also 
affect it (attraction and repulsion process, respectively) [144]. More information about the EFO mechanism can be found in the related literature $[145 ; 146]$.

Shuffled complex evolution was designed by Duan et al. [147]. This algorithm draws on four major concepts including (i) synthesizing probabilistic and deterministic theories, (ii) performing systematic evolutions on so-called containers "complexes", (iii) doing competitive evolutions, and (4) shuffling the complexes. Scattering the points is the initial step. Considering the function value of the points, they are then sorted in ascending order. Next, the points are partitioned into a number of complexes where each of them can independently evolve and search the viable space. By applying the modified simplex method of Nelder and Mead [148] for global enhancement, some points are chosen from each unit to form a sub-complex. The larger the fitness of the point is, the more the likelihood of generating offspring is. The worst points are replaced by the new offspring [149]. Studies like [150; 151] have explained the SCE in more detail.

\section{Data collection}

As is known, the settlement $\left(U_{y}\right)$ of a footing is a function of several parameters. In this work, the effect of friction angle (FA), setback distance (SD), elastic modulus (EM), unit weight (UW), dilation angle (DA), applied stress (AS), and Poisson's ratio (PR) is incorporated for measuring the settlement by a series of finite element analysis executed on a two-layered soil system that bears a shallow footing.

Figure 1 depicts the histogram chart of the mentioned parameters. According to the statistical indicators, the values of FA, SD, EM, UW, DA, AS, and PR range in [30, 42], [1, 7] $m,[17500$, 65000] $\frac{k N}{m^{2}},[19.0,21.1] \frac{k N}{m^{3}},[3.4,11.5],[0.0,1132.6] \frac{\mathrm{kN}}{\mathrm{m}}$, and [0.2490, 0.3330]. Also the target parameter (i.e., the $U_{y}$ ) varies from 0 to $0.10 \mathrm{~m}$.

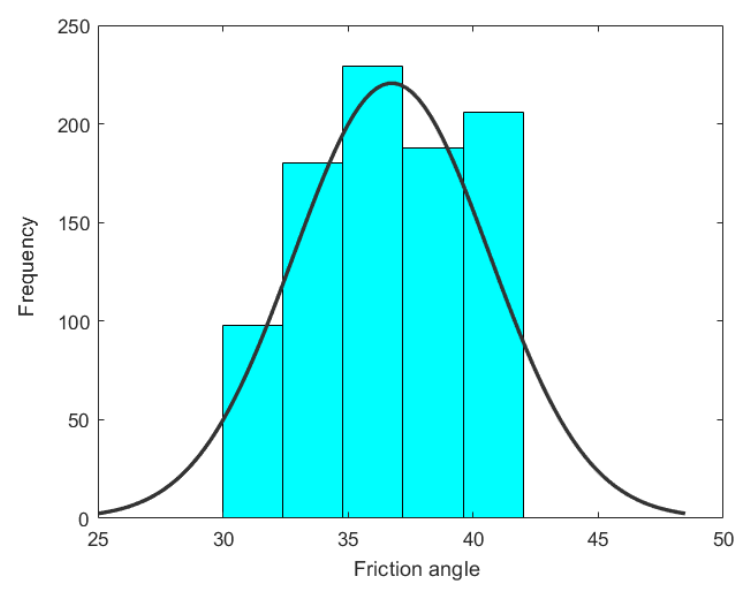

(a)

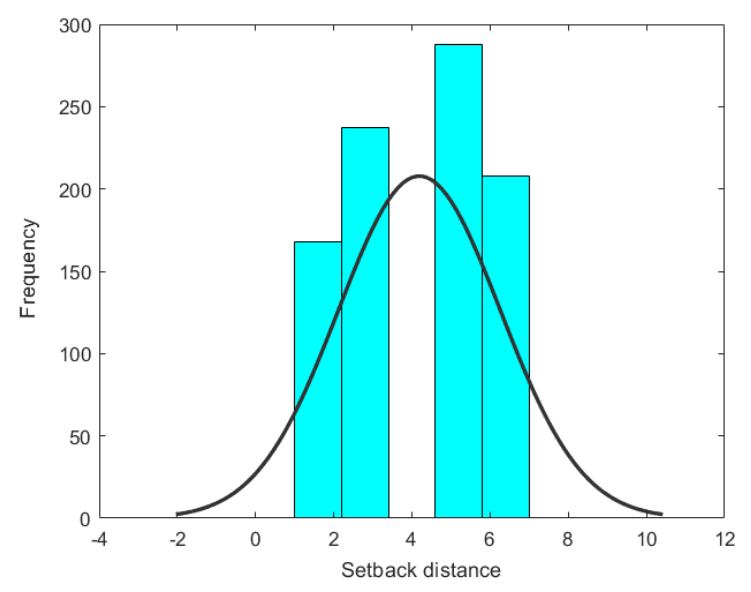

(b) 


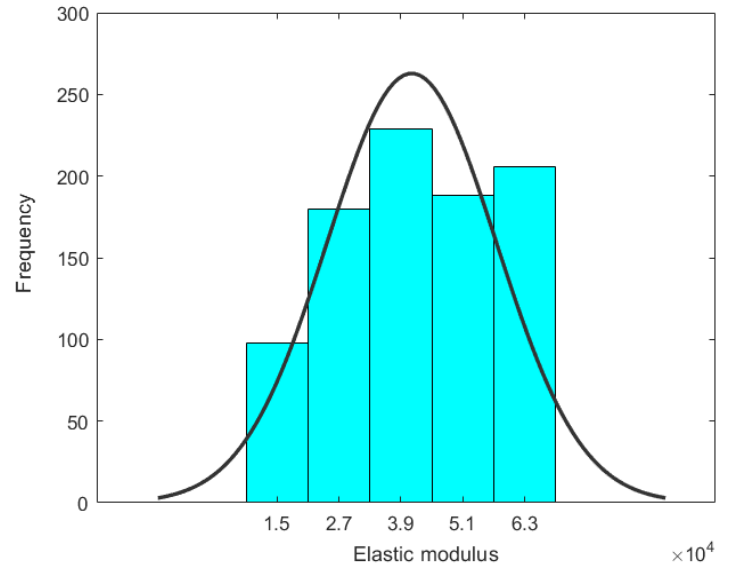

(c)

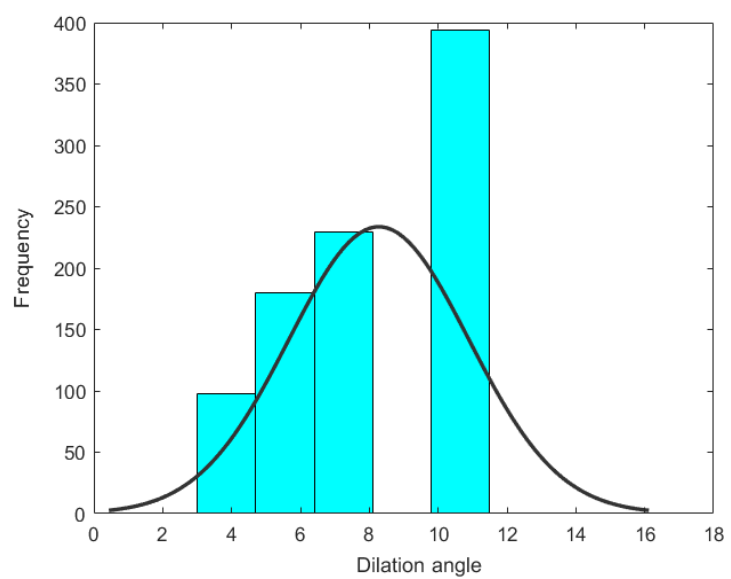

(e)

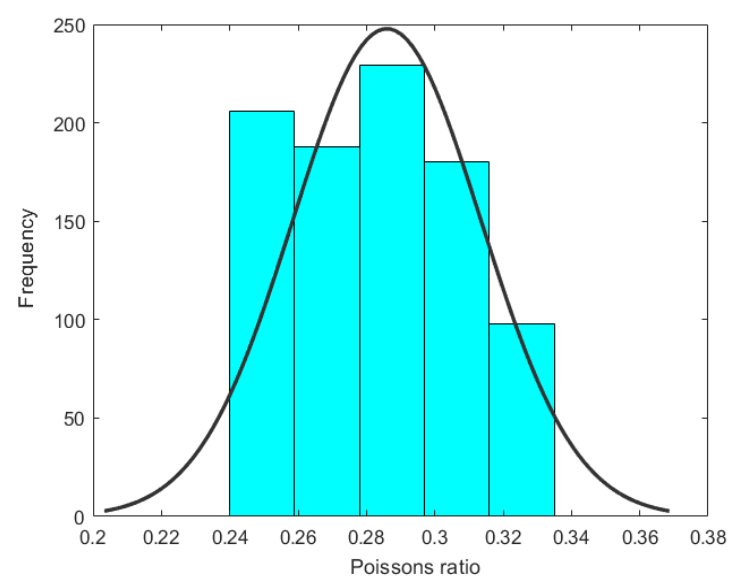

$(\mathrm{g})$

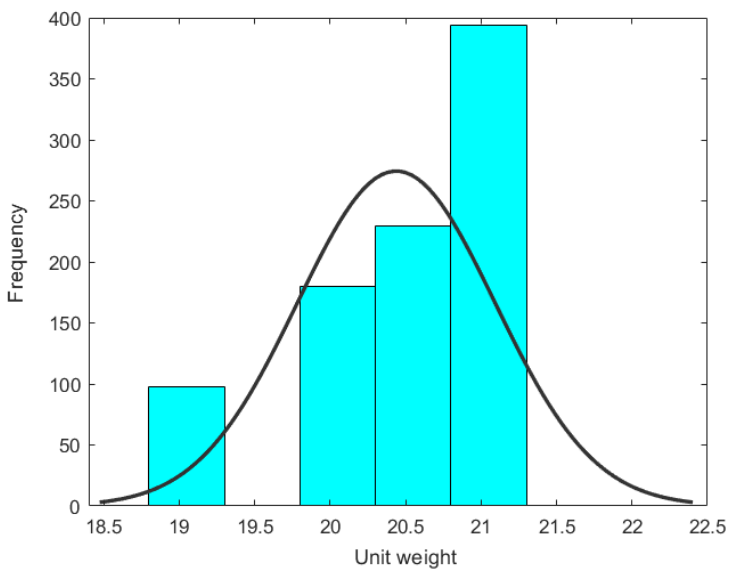

(d)

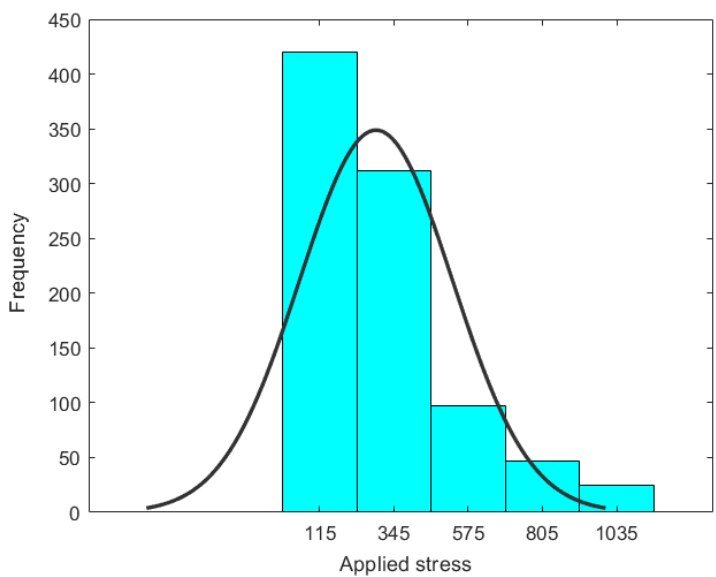

(f)

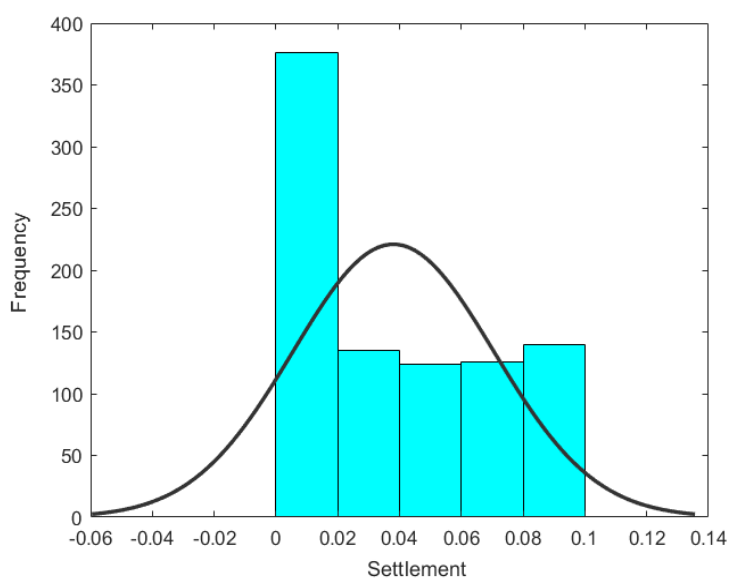

(h)

Figure 1: Histogram diagram of the parameters of the prepared dataset.

With reference to different conditions for this problem, a total of 901 Uys were recorded for the executed stages. The statistical indicators of mean, standard error, standard deviation, and sample variance are $0.0380,0.0011,0.0325$, and 0.0011 , respectively, for the obtained $U y$ values. After writing the settlements in front of the corresponding input parameters, the data were permuted randomly and 721 samples (around $80 \%$ of records) were selected for exploring the $U y$ behavior. 


\section{Results and discussion}

This research is an effort to find an appropriate novel trainer of ANN in examining the bearing capacity of a shallow foundation. To achieve this, a hybrid of WCA and MLP is created and applied to predict the settlement of the foundation. The quality of the prediction is addressed by using three accuracy indicators of Pearson correlation coefficient (R), mean absolute error (MAE), and root mean square error (RMSE). Given $U_{y} i_{\text {predicted }}$ and $U_{y i_{\text {expected }}}$ as the simulated and real $U_{y} \mathrm{~s}$, respectively, Equations 13 to 15 formulate the R, MAE, and RMSE.

$$
\begin{aligned}
& R=\frac{\sum_{i=1}^{G}\left(U_{y i_{\text {prediced }}}-\bar{U}_{y_{\text {predicted }}}\right)\left(U_{y i_{\text {expected }}}-\bar{U}_{y_{\text {expected }}}\right)}{\sqrt{\sum_{i=1}^{G}\left(U_{y i_{\text {predicted }}}-\bar{U}_{y_{\text {predicted }}}\right)^{2}} \sqrt{\sum_{i=1}^{G}\left(U_{y i_{\text {expected }}}-\bar{U}_{y_{\text {expected }}}\right)^{2}}} \\
& M A E=\frac{1}{G} \sum_{i=1}^{G}\left|U_{y i_{\text {eppectad }}}-U_{y i_{\text {preticad }}}\right| \\
& R M S E=\sqrt{\frac{1}{G} \sum_{i=1}^{G}\left[\left(U_{y i_{\text {expected }}}-U_{y i_{\text {predicted }}}\right)\right]^{2}}
\end{aligned}
$$

\subsection{WCA-MLP results}

The implementation of any neuro-metaheuristic model consists of several steps. The WCA-MLP is first created by assigning the WCA as the trainer of an MLP network with a $7 \times 7 \times 1$ architecture. As explained, initializing the parameters of the algorithm is the first step. Based on a trial and error process, $d_{\max }$ and $K_{s r}$ were set to be $1 \mathrm{e}-16$ and 4 , respectively. Also, examining the convergence behavior of the WCA indicated the suitability of 1000 for the maximum number of iterations. The population size $\left(N_{p o p}\right)$ is another effective factor that was optimized by testing nine values. The convergence curves of the tested models are shown in Figure 2. In this figure, the objective function (on the $y$-axis) is the RMSE of the training data. 


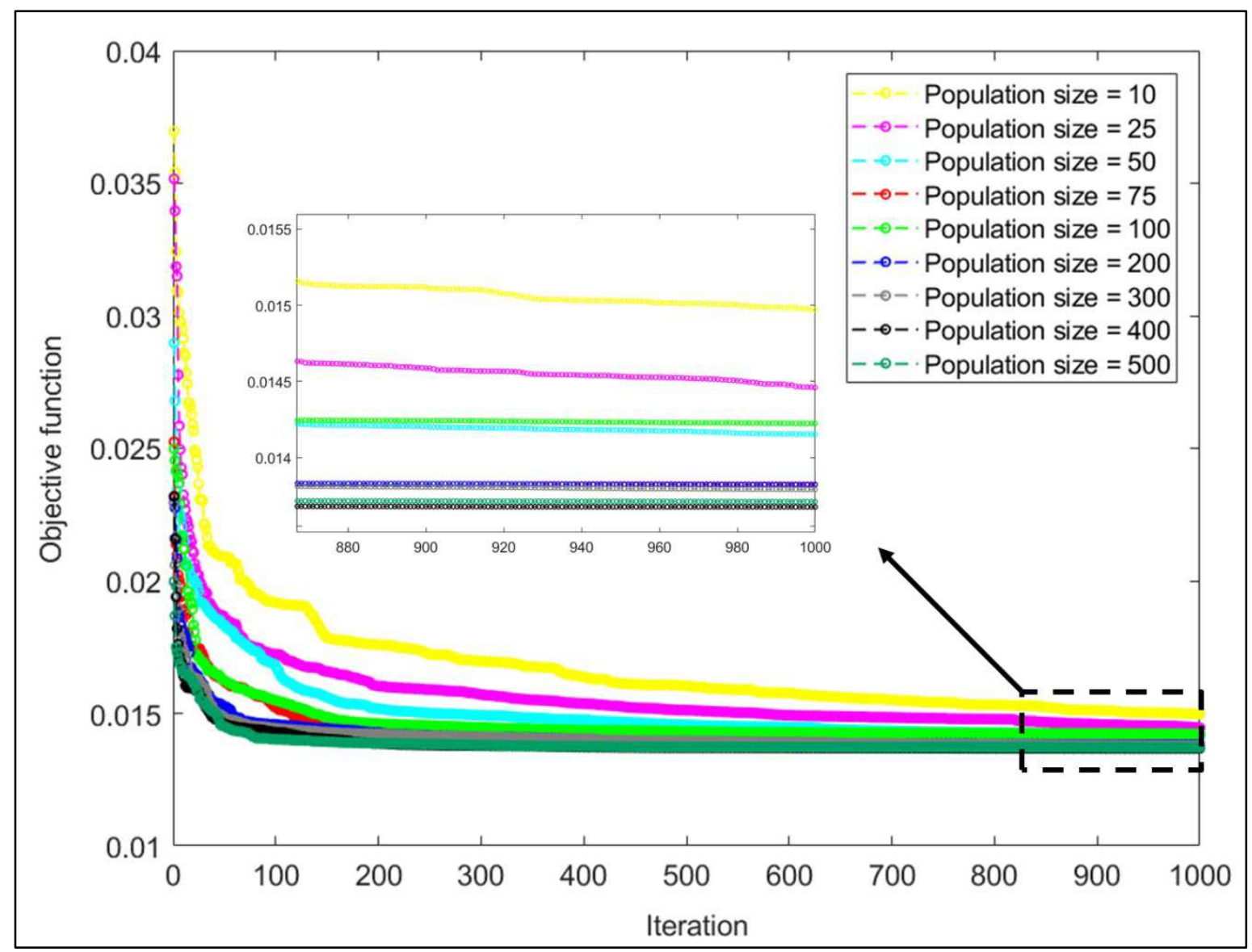

Figure 2: The sensitivity of the WCA performance to the population size.

This practice revealed that the best results are yielded by the WCA-MLP with $N_{\text {pop }}=400$. The corresponding RMSE was 0.013677 . This value, as well as the MAE $=0.0094281$, indicates an acceptable level of accuracy in understanding the $U_{y}$ behavior. As for predicting this pattern, the RMSE and MAE were 0.015175 and 0.010515 , respectively.

As is shown in Figure 3, the correlation for both phases is around $90 \%$ which implies a good agreement between the expected and modeled $U_{y} \mathrm{~s}$. The $\mathrm{R}$ indices were exactly 0.90527 and 0.89365 for the training and testing samples. 


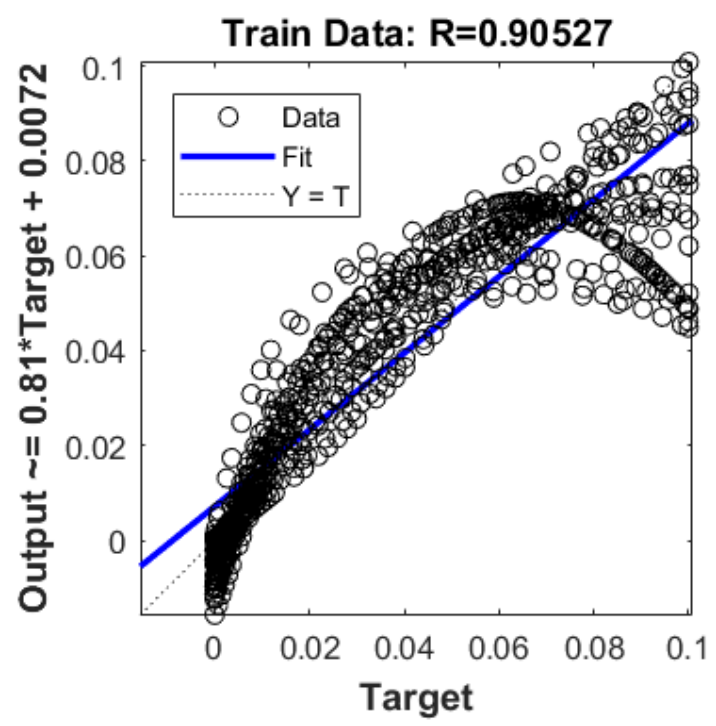

(a)

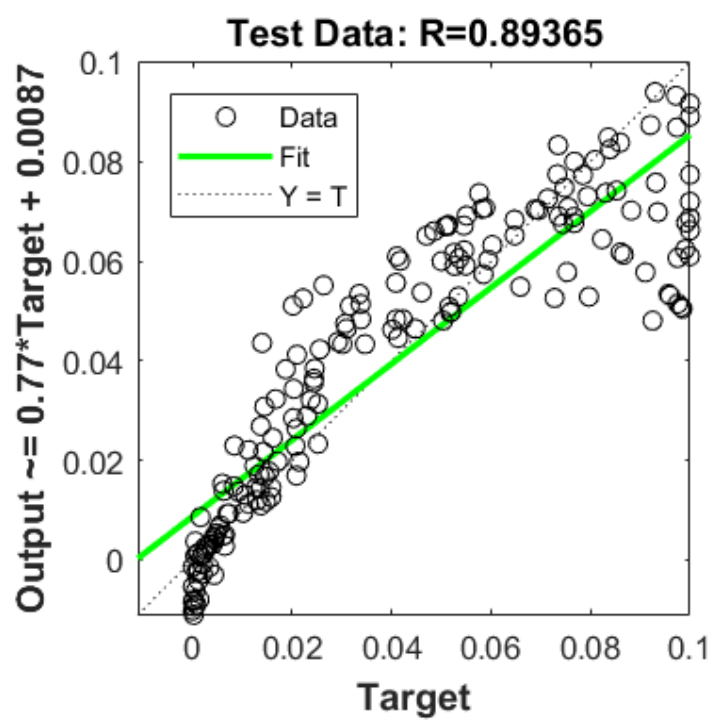

(b)

Figure 3: The regression charts of the (a) training and (b) testing results for the WCA-MLP.

\subsection{Benchmark results}

The EFO-MLP and SCE-MLP were developed in the same way and predicted the $U_{y}$. The convergence curves of these models are illustrated in Figure 4. As is seen, the EFO required 5000 iterations to reach a stable convergence during training the MLP. Note that, the $N_{p o p}$ for the EFO and SCE were 25 and 10 determined by a trial and error practice.

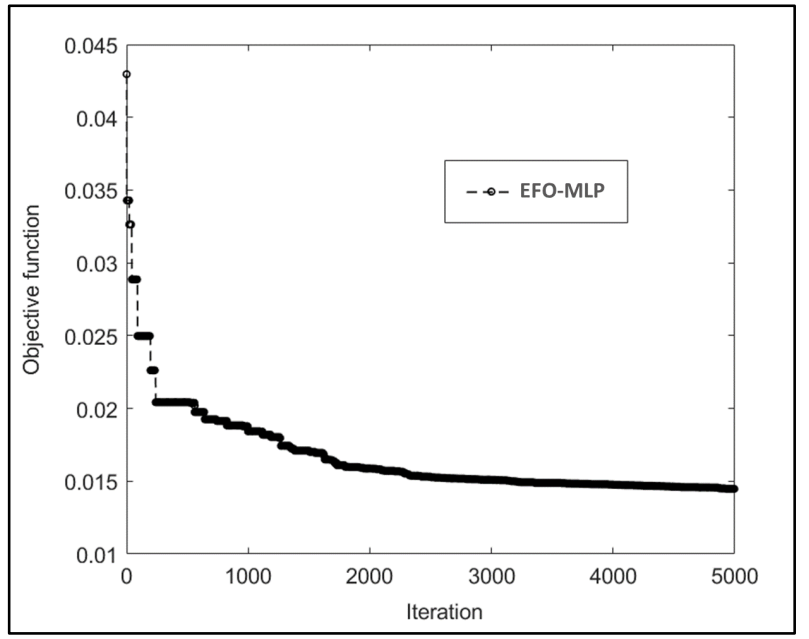

(a)

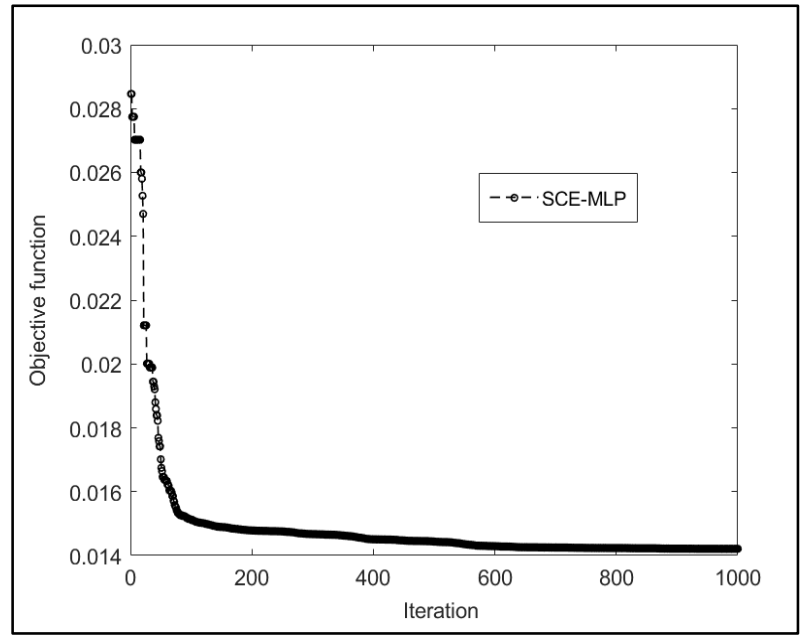

(b)

Figure 4: The convergence curves of the benchmark methods.

According to the training results, these methods could satisfactorily analyze the relationship between this parameter and related factors. The RMSEs for these two models were close (i.e., 0.014476 and 
0.014209). Likewise, the MAEs of 0.010383 and 0.010042 indicated a similar level of accuracy for both models in training the ANN. In the testing phase, the RMSEs of 0.015455 and 0.015484 along with the MAEs of 0.011104 and 0.010976 proved that the used models can present a reliable prediction of the intended parameter.

Figure 5 depicts the regression charts of these models. The R values of 0.89331 and 0.89743 are obtained for the training data and 0.88973 and 0.89001 are obtained for the testing data of the EFOMLP and SCE-MLP models. These results demonstrate that the produced $U_{y}$ are well correlated with the expected values.

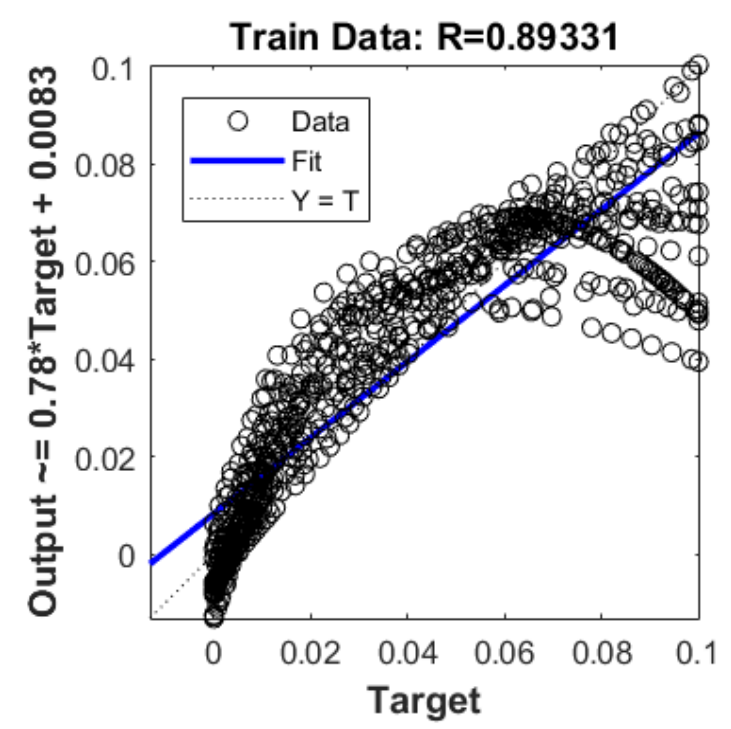

(a)

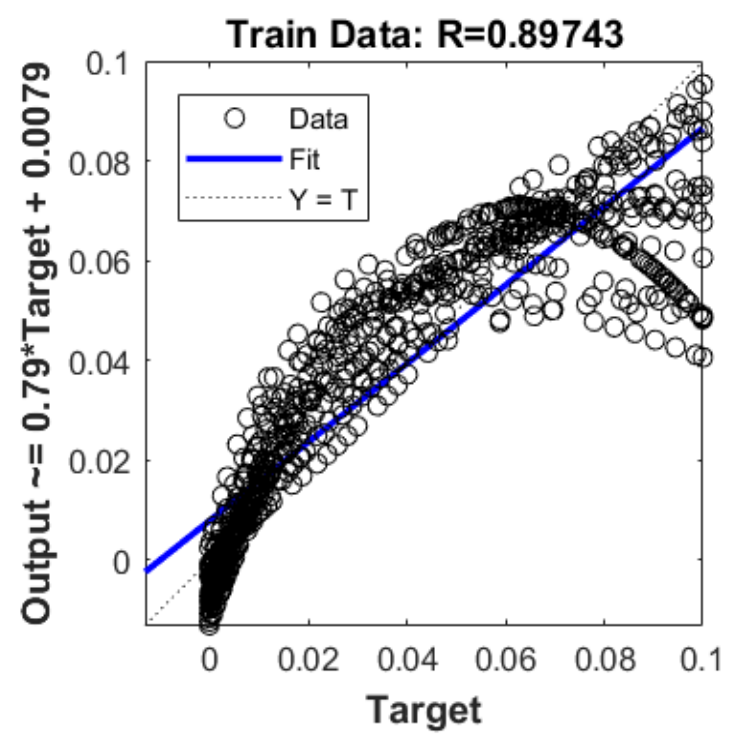

(c)

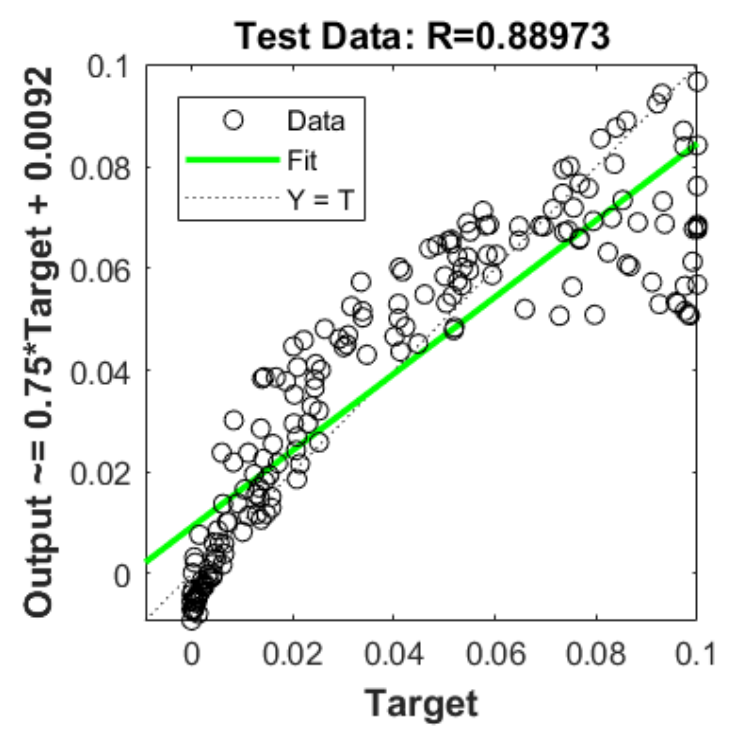

(b)

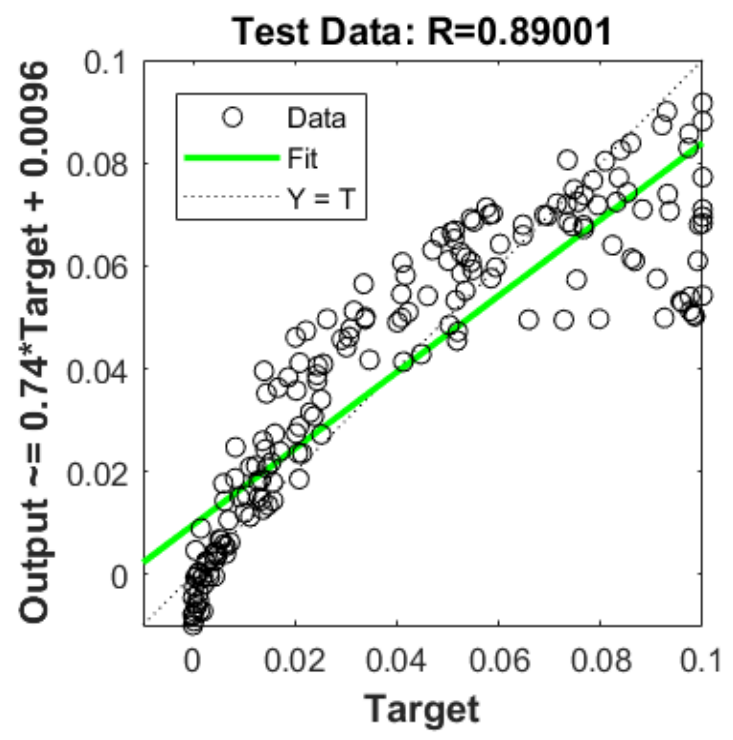

(d) 
Figure 5: The regression charts of the training and testing results for the ( $a$ and b) EFO-MLP and (c and d) SCE-MLP.

\subsection{Comparison}

From two previous sections, it can be derived that all three metaheuristic algorithms (WCA, EFO, and SCE) could act as a capable trainer for the MLP neural network. In this section, the performance of the proposed algorithm is compared with benchmark ones.

Figure 6 shows graphical views of the training and testing errors calculated for the outputs of the used models. It can be seen that the errors obtained from the WCA-optimized model are more aggregated near the ideal line $($ Error $=0)$.

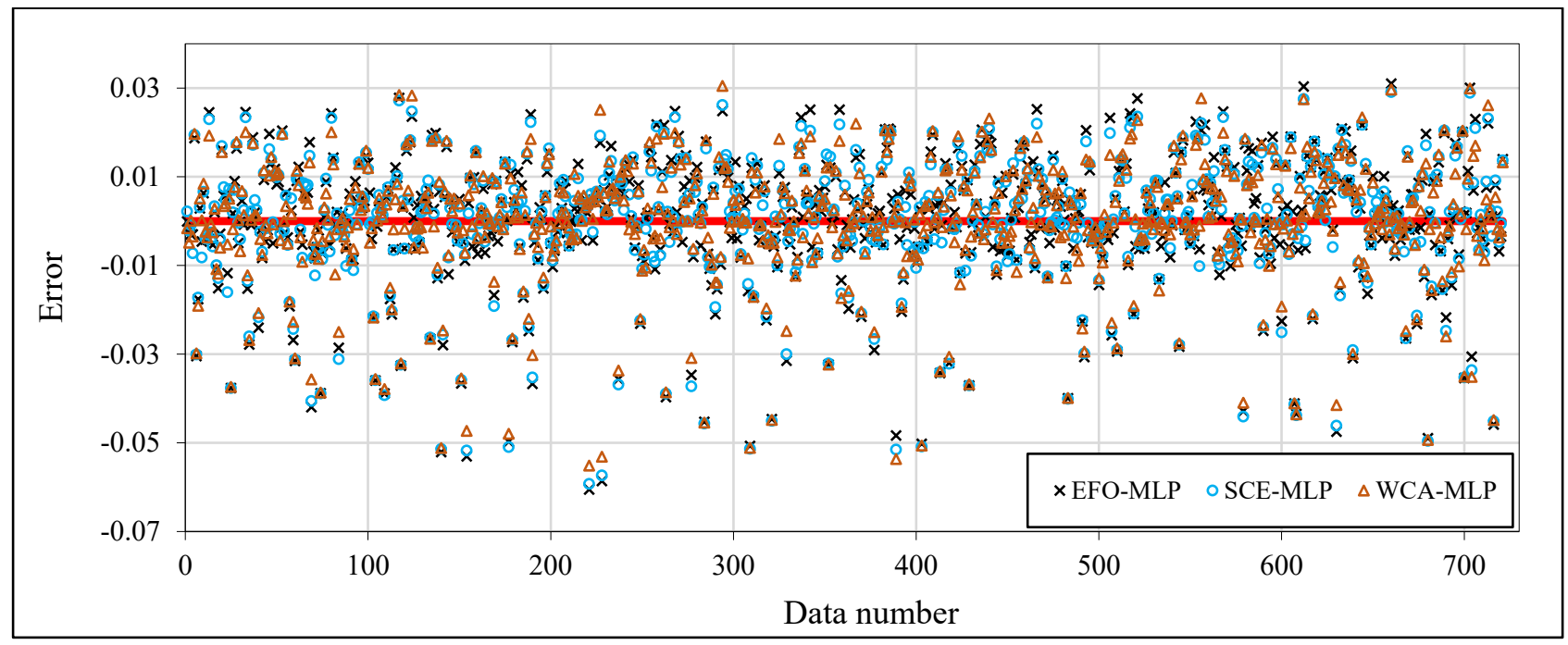

(a)

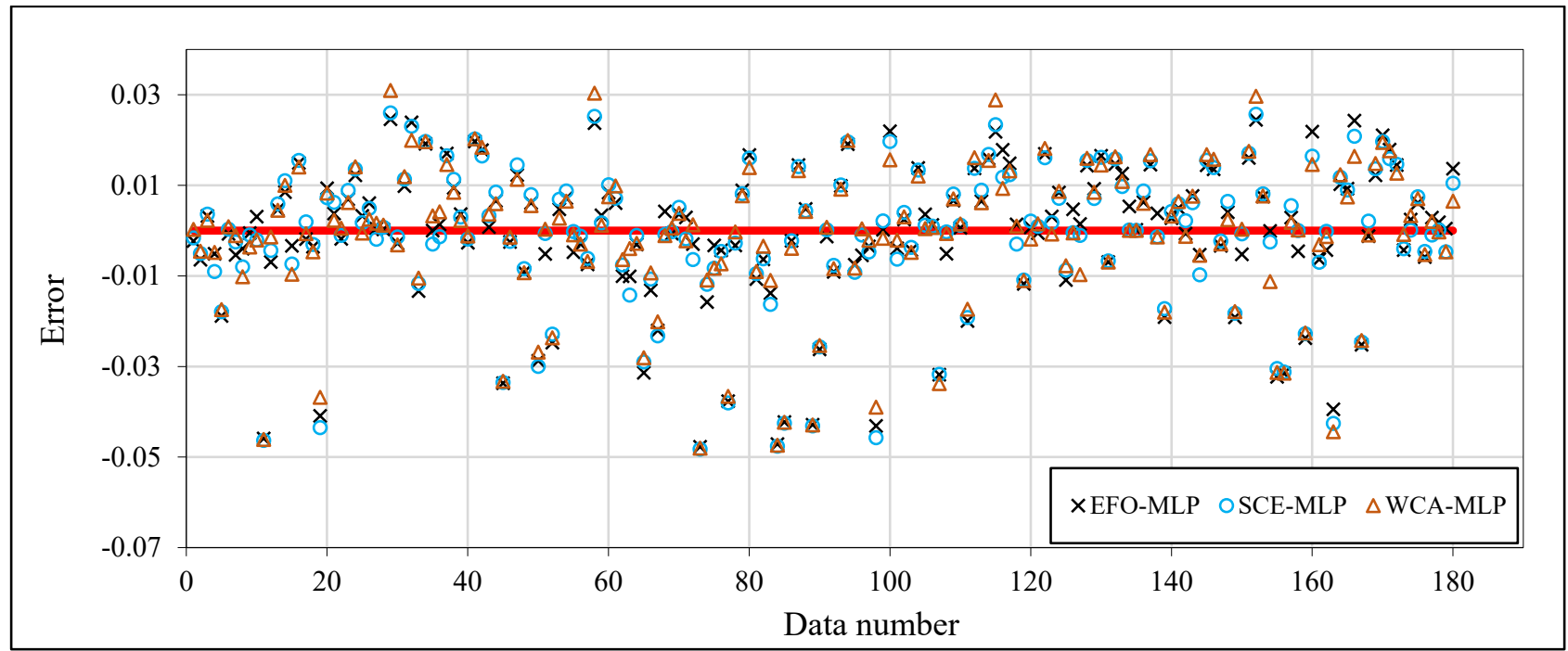

(b)

Figure 6: A graphical comparison of the (a) training and (b) testing errors for all used models. 
Moreover, in terms of all accuracy indicators, the prediction of the WCA-MLP was more accurate than EFO-MLP and SCE-MLP. For example, examining the training RMSEs showed that the error of the EFO-MLP and SCE-MLP is 5.84 and 3.89\% larger than WCA-MLP (relative to the WCAMLP). These values were 1.85 and $2.04 \%$ for the testing data. Considering the role of the metaheuristic algorithms in combination with the neural system, it is deduced that the MLP configuration designed by the WCA performs more reliably than the other two search strategies.

The time taken by the used algorithms for finding the optimal responses is considered, too. While the WCA trained the ANN in 4807.8 seconds, the EFO and SCE needed around 48.9 and 546.5 seconds. Notably, the system used for executing the algorithms was a personal computer with the CPU of Intel core 17 with 16 gigs of RAM). Concerning the reasons for these distinctions, apart from the essence of searching strategies, the benchmark models were implemented with simpler configurations (i.e., smaller $\left.N_{p o p} \mathbf{s}\right)$.

\subsection{The formula of the WCA-MLP}

In this section, the explicit formula of the WCA-MLP is exhibited as a series of linear/non-linear relationships. Figure 7 shows the architecture of the MLP neural network used for approximating the $U_{y}$ from FA, SD, EM, UW, DA, AS, and PR.

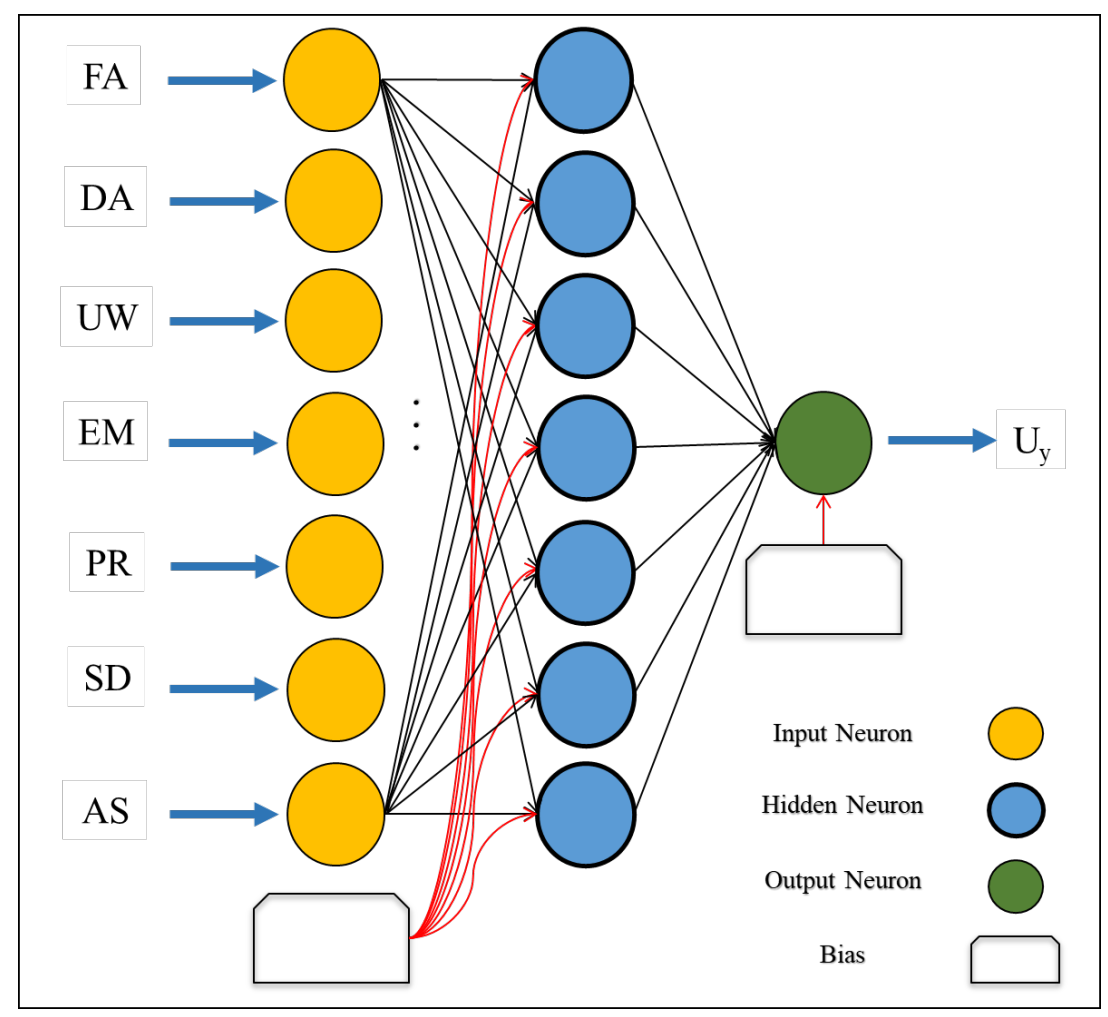

Figure 7: The neural structure of the used predictive model.

The $U_{y}$ is calculated as follows: 


$$
\begin{aligned}
& U_{y}=-0.023666 \times \mathrm{HO}_{1}+0.901186 \times \mathrm{HO}_{2}-0.643029 \times \mathrm{HO}_{3}+0.945461 \times \mathrm{HO}_{4}-0.716870 \\
& \times \mathrm{HO}_{5}-0.788679 \times \mathrm{HO}_{6}-0.104387 \times \mathrm{HO}_{7}+0.465768
\end{aligned}
$$

where

$$
H O_{i}=\frac{2}{1+e^{-2 \times s_{i}}}-1
$$

in which

$$
\begin{aligned}
& S_{1}=1.084288 \times F A+0.595115 \times D A+0.291941 \times U W+1.247339 \times E M+0.391523 \times \\
& P R-0.138593 \times S D-0.272225 \times A S-1.848657 \\
& S_{2}=-0.249199 \times F A-0.755865 \times D A-0.986040 \times U W-0.972855 \times E M-0.144769 \times \\
& P R+0.130731 \times S D+0.909577 \times A S+1.232438 \\
& S_{3}=1.023457 \times F A-0.043397 \times D A+0.855424 \times U W+0.984439 \times E M+0.515326 \times \\
& P R-0.177398 \times S D-0.608510 \times A S-0.616219 \\
& S_{4}=-0.158531 \times F A 0.271860 \times D A-1.049325 \times U W-1.325108 \times E M+0.375280 \times \\
& P R-0.145215 \times S D-0.547336 \times A S+0.000000 \\
& S_{5}=-0.607473 \times F A-0.701226 \times D A-1.026808 \times U W-0.867166 \times E M-0.420470 \times \\
& P R-0.103031 \times S D-0.750380 \times A S-0.616219 \\
& S_{6}=0.773196 \times F A+0.180922 \times D A-1.280874 \times U W+0.700894 \times E M-0.298608 \times \\
& P R+0.712766 \times S D-0.240574 \times A S+1.232438 \\
& S_{7}=-0.051134 \times F A+0.712179 \times D A+0.311052 \times U W-0.103681 \times E M-0.963517 \times \\
& P R+1.000864 \times S D-0.932803 \times A S-1.848657
\end{aligned}
$$

The numbers used in the above equations represent the weights and biases of the MLP optimally found by the WCA during minimizing the learning error. Equation 16 releases the $U_{y}$ by doing a linear computation on hidden outputs $\left(\mathrm{HO}_{i}\right)$. As Equation 17 denotes, calculating $\mathrm{HO}_{1}, \mathrm{HO}_{2}, \ldots$, and $\mathrm{HO}_{7}$ consists in obtaining $s_{1}, s_{2}, \ldots$, and $s_{7}$ from Equations 18 to 24, respectively. In fact, Equation 17 represents a so-called activation function "Tansig" that is used for the neurons in the hidden layer. According to many previous studies, Tansig is a suitable function that can nicely deal with abrupt changes in the dataset $[152 ; 153]$.

\section{Conclusions}

The methods based on neural computing have been popularly used for bearing capacity analysis. In this work, the water cycle algorithm, electromagnetic field optimization, and shuffled complex evolution algorithms were appointed for training an MLP neural network in approximating the settlement of a shallow foundation. The main conclusions are as follows:

- Implementing the models by their optimal parameters results in a higher quality of training. 
- Compared to the EFO and SCE, the WCA needs a considerably larger population for accomplishing the optimization ( $N_{p o p}$ s of 400 vs. 25 and 10). Also, the EFO was implemented 5000 times to reach a stable situation.

- Based on more than $88 \%$ correlation of the outputs in all stages, the used hybrid models can properly capture and reproduce the $U_{y}$ behavior.

- The WCA-MLP surpassed the other two models in terms of all RMSE, MAE, and R accuracy indicators. In other words, the searching strategy of this algorithm could find a more promising solution to the given problem (i.e., setting the appropriate configuration of the MLP).

- The tested WCA-ANN can be used for accurate analysis of the $U_{y}$ in practice.

\section{Conflict of interest:}

Authors declare no conflict of interest.

\section{References}

1. Xu M, Li T, Wang Z, Deng X, Yang R, Guan Z (2018) Reducing Complexity of HEVC: A Deep Learning Approach. IEEE Transactions on Image Processing 27: 5044-5059, 10.1109/TIP.2018.2847035.

2. Li T, Xu M, Zhu C, Yang R, Wang Z, Guan Z (2019) A Deep Learning Approach for Multi-Frame In-Loop Filter of HEVC. IEEE Transactions on Image Processing 28: 5663-5678, 10.1109/TIP.2019.2921877.

3. Qiu T, Shi X, Wang J, Li Y, Qu S, Cheng Q, Cui T, Sui S (2019) Deep Learning: A Rapid and Efficient Route to Automatic Metasurface Design. Advanced Science 6: 1900128, https://doi.org/10.1002/advs.201900128.

4. Chen H, Chen A, Xu L, Xie H, Qiao H, Lin Q, Cai K (2020) A deep learning CNN architecture applied in smart nearinfrared analysis of water pollution for agricultural irrigation resources. Agricultural Water Management 240: 106303,

5. Lv Z, Qiao L (2020) Deep belief network and linear perceptron based cognitive computing for collaborative robots. Applied Soft Computing 92: 106300, https://doi.org/10.1016/j.asoc.2020.106300.

6. Qian J, Feng S, Li Y, Tao T, Han J, Chen Q, Zuo C (2020) Single-shot absolute 3D shape measurement with deeplearning-based color fringe projection profilometry. Optics Letters 45: 1842-1845,

7. Qian J, Feng S, Tao T, Hu Y, Li Y, Chen Q, Zuo C (2020) Deep-learning-enabled geometric constraints and phase unwrapping for single-shot absolute 3D shape measurement. APL Photonics 5: 046105, https://doi.org/10.1063/5.0003217.

8. Liu S, Chan FTS, Ran W (2016) Decision making for the selection of cloud vendor: An improved approach under group decision-making with integrated weights and objective/subjective attributes. Expert Systems with Applications 55: 37-47, https://doi.org/10.1016/j.eswa.2016.01.059.

9. Wu C, Wu P, Wang J, Jiang R, Chen M, Wang X (2020) Critical review of data-driven decision-making in bridge operation and maintenance. Structure and Infrastructure Engineering 1-24, 10.1080/15732479.2020.1833946.

10. Cao B, Zhao J, Lv Z, Gu Y, Yang P, Halgamuge SK (2020) Multiobjective Evolution of Fuzzy Rough Neural Network via Distributed Parallelism for Stock Prediction. IEEE Transactions on Fuzzy Systems 28: 939-952,

11. Quan Q, Hao Z, Xifeng H, Jingchun L (2020) Research on water temperature prediction based on improved support vector regression. Neural Computing and Applications 1-10, https://doi.org/10.1007/s00521-020-04836-4.

12. Shi K, Wang J, Tang Y, Zhong S (2020) Reliable asynchronous sampled-data filtering of T-S fuzzy uncertain delayed neural networks with stochastic switched topologies. Fuzzy Sets and Systems 381: 1-25,

13. Shi K, Wang J, Zhong S, Tang Y, Cheng J (2020) Non-fragile memory filtering of T-S fuzzy delayed neural networks based on switched fuzzy sampled-data control. Fuzzy Sets and Systems 394: 40-64, https://doi.org/10.1016/j.fss.2019.09.001.

14. Zhu Q (2020) Research on Road Traffic Situation Awareness System Based on Image Big Data. IEEE Intelligent Systems 35: 18-26, 10.1109/MIS.2019.2942836.

15. Zhao X, Ye Y, Ma J, Shi P, Chen H (2020) Construction of electric vehicle driving cycle for studying electric vehicle energy consumption and equivalent emissions. Environmental Science and Pollution Research 1-15, https://doi.org/10.1007/s11356-020-09094-4. 
16. Zhang T, Wu X, Li H, Tsang DCW, Li G, Ren H (2020) Struvite pyrolysate cycling technology assisted by thermal hydrolysis pretreatment to recover ammonium nitrogen from composting leachate. Journal of Cleaner Production 242 : 118442, https://doi.org/10.1016/j.jclepro.2019.118442.

17. Zhang K, Ruben GB, Li X, Li Z, Yu Z, Xia J, Dong Z (2020) A comprehensive assessment framework for quantifying climatic and anthropogenic contributions to streamflow changes: A case study in a typical semi-arid North China basin. Environmental Modelling \& Software 128: 104704, https://doi.org/10.1016/j.envsoft.2020.104704.

18. Yang W, Zhao Y, Wang D, Wu H, Lin A, He L (2020) Using Principal Components Analysis and IDW Interpolation to Determine Spatial and Temporal Changes of Surface Water Quality of Xin'anjiang River in Huangshan, China. International Journal of Environmental Research and Public Health 17: 2942,

19. Wang Y, Yuan Y, Wang Q, Liu C, Zhi Q, Cao J (2020) Changes in air quality related to the control of coronavirus in China: Implications for traffic and industrial emissions. Science of The Total Environment 731: 139133, https://doi.org/10.1016/j.scitotenv.2020.139133.

20. Wang S, Zhang K, van Beek LPH, Tian X, Bogaard TA (2020) Physically-based landslide prediction over a large region: Scaling low-resolution hydrological model results for high-resolution slope stability assessment. Environmental Modelling \& Software 124: 104607, https://doi.org/10.1016/j.envsoft.2019.104607.

21. Liu J, Liu Y, Wang X (2020) An environmental assessment model of construction and demolition waste based on system dynamics: a case study in Guangzhou. Environmental Science and Pollution Research 27: 37237-37259, 10.1007/s11356-019-07107-5.

22. Jia L, Liu B, Zhao Y, Chen W, Mou D, Fu J, Wang Y, Xin W, Zhao L (2020) Structure design of MoS2@Mo2C on nitrogen-doped carbon for enhanced alkaline hydrogen evolution reaction. Journal of Materials Science 55: 16197-16210, $10.1007 / \mathrm{s} 10853-020-05107-2$.

23. He L, Shao F, Ren L (2020) Sustainability appraisal of desired contaminated groundwater remediation strategies: an information-entropy-based stochastic multi-criteria preference model. Environment, Development and Sustainability 121, https://doi.org/10.1007/s10668-020-00650-z.

24. Chao L, Zhang K, Li Z, Zhu Y, Wang J, Yu Z (2018) Geographically weighted regression based methods for merging satellite and gauge precipitation. Journal of Hydrology 558: 275-289, https://doi.org/10.1016/j.jhydrol.2018.01.042.

25. He L, Shao F, Ren L (2020) Sustainability appraisal of desired contaminated groundwater remediation strategies: an information-entropy-based stochastic multi-criteria preference model. Environment, Development and Sustainability 10.1007/s10668-020-00650-Z.

26. Zhang T, He X, Deng Y, Tsang DCW, Yuan H, Shen J, Zhang S (2020) Swine manure valorization for phosphorus and nitrogen recovery by catalytic-thermal hydrolysis and struvite crystallization. Science of The Total Environment 729 : 138999, https://doi.org/10.1016/j.scitotenv.2020.138999.

27. Han X, Zhang D, Yan J, Zhao S, Liu J (2020) Process development of flue gas desulphurization wastewater treatment in coal-fired power plants towards zero liquid discharge: Energetic, economic and environmental analyses. Journal of Cleaner Production 261: 121144, https://doi.org/10.1016/j.jclepro.2020.121144.

28. Feng S, Lu H, Tian P, Xue Y, Lu J, Tang M, Feng W (2020) Analysis of microplastics in a remote region of the Tibetan Plateau: Implications for natural environmental response to human activities. Science of The Total Environment 739: 140087, https://doi.org/10.1016/j.scitotenv.2020.140087.

29. Zhang T, Wu X, Fan X, Tsang DCW, Li G, Shen Y (2019) Corn waste valorization to generate activated hydrochar to recover ammonium nitrogen from compost leachate by hydrothermal assisted pretreatment. Journal of Environmental Management 236: 108-117, https://doi.org/10.1016/j.jenvman.2019.01.018.

30. Keshtegar B, Heddam S, Sebbar A, Zhu S-P, Trung N-T (2019) SVR-RSM: a hybrid heuristic method for modeling monthly pan evaporation. Environmental Science and Pollution Research 26: 35807-35826,

31. Hu X, Chong H-Y, Wang X (2019) Sustainability perceptions of off-site manufacturing stakeholders in Australia. Journal of Cleaner Production 227: 346-354, https://doi.org/10.1016/j.jclepro.2019.03.258.

32. He L, Shen J, Zhang Y (2018) Ecological vulnerability assessment for ecological conservation and environmental management. Journal of Environmental Management 206: 1115-1125, https://doi.org/10.1016/j.jenvman.2017.11.059.

33. He L, Chen Y, Zhao H, Tian P, Xue Y, Chen L (2018) Game-based analysis of energy-water nexus for identifying environmental impacts during Shale gas operations under stochastic input. Science of The Total Environment 627: 15851601, https://doi.org/10.1016/j.scitotenv.2018.02.004.

34. Zhang K, Wang Q, Chao L, Ye J, Li Z, Yu Z, Yang T, Ju Q (2019) Ground observation-based analysis of soil moisture spatiotemporal variability across a humid to semi-humid transitional zone in China. Journal of Hydrology 574: 903-914, https://doi.org/10.1016/j.jhydrol.2019.04.087.

35. Chen Y, Li J, Lu H, Yan P (2021) Coupling system dynamics analysis and risk aversion programming for optimizing the mixed noise-driven shale gas-water supply chains. Journal of Cleaner Production 278: 123209, https://doi.org/10.1016/j.jclepro.2020.123209.

36. Li X, Zhang R, Zhang X, Zhu P, Yao T (2020) Silver-Catalyzed Decarboxylative Allylation of Difluoroarylacetic Acids with Allyl Sulfones in Water. Chemistry - An Asian Journal 15: 1175-1179, https://doi.org/10.1002/asia.202000059.

37. He L, Chen Y, Li J (2018) A three-level framework for balancing the tradeoffs among the energy, water, and airemission implications within the life-cycle shale gas supply chains. Resources, Conservation and Recycling 133: 206228, https://doi.org/10.1016/j.resconrec.2018.02.015. 
38. Chen Y, He L, Li J, Zhang S (2018) Multi-criteria design of shale-gas-water supply chains and production systems towards optimal life cycle economics and greenhouse gas emissions under uncertainty. Computers \& Chemical Engineering 109: 216-235, https://doi.org/10.1016/j.compchemeng.2017.11.014.

39. Cheng X, He L, Lu H, Chen Y, Ren L (2016) Optimal water resources management and system benefit for the Marcellus shale-gas reservoir in Pennsylvania and West Virginia. Journal of Hydrology 540: 412-422, https://doi.org/10.1016/j.jhydrol.2016.06.041.

40. Yang M, Sowmya A (2015) An Underwater Color Image Quality Evaluation Metric. IEEE Transactions on Image Processing 24: 6062-6071, 10.1109/TIP.2015.2491020.

41. Feng W, Lu H, Yao T, Yu Q (2020) Drought characteristics and its elevation dependence in the Qinghai-Tibet plateau during the last half-century. Scientific Reports 10: 14323, 10.1038/s41598-020-71295-1.

42. Zhu L, Kong L, Zhang C (2020) Numerical Study on Hysteretic Behaviour of Horizontal-Connection and EnergyDissipation Structures Developed for Prefabricated Shear Walls. Applied Sciences 10: 1240, https://doi.org/10.3390/app10041240.

43. Zhang W (2020) Parameter Adjustment Strategy and Experimental Development of Hydraulic System for Wave Energy Power Generation. Symmetry 12: 711,

44. Yang Y, Liu J, Yao J, Kou J, Li Z, Wu T, Zhang K, Zhang L, Sun H (2020) Adsorption behaviors of shale oil in kerogen slit by molecular simulation. Chemical Engineering Journal 387: 124054, https://doi.org/10.1016/j.cej.2020.124054.

45. Yan J, Pu W, Zhou S, Liu H, Bao Z (2020) Collaborative detection and power allocation framework for target tracking in multiple radar system. Information Fusion 55: 173-183, https://doi.org/10.1016/j.inffus.2019.08.010.

46. Wang Y, Yao M, Ma R, Yuan Q, Yang D, Cui B, Ma C, Liu M, Hu D (2020) Design strategy of barium titanate/polyvinylidene fluoride-based nanocomposite films for high energy storage. Journal of Materials Chemistry A 8: 884-917, https://doi.org/10.1039/C9TA11527G.

47. Lv Q, Liu H, Yang D, Liu H (2019) Effects of urbanization on freight transport carbon emissions in China: Common characteristics and regional disparity. Journal of Cleaner Production 211: 481-489, https://doi.org/10.1016/j.jclepro.2018.11.182.

48. Lu H, Tian P, He L (2019) Evaluating the global potential of aquifer thermal energy storage and determining the potential worldwide hotspots driven by socio-economic, geo-hydrologic and climatic conditions. Renewable and Sustainable Energy Reviews 112: 788-796, https://doi.org/10.1016/j.rser.2019.06.013.

49. Zhang B, Xu D, Liu Y, Li F, Cai J, Du L (2016) Multi-scale evapotranspiration of summer maize and the controlling meteorological factors in north China. Agricultural and Forest Meteorology 216: 1-12, https://doi.org/10.1016/j.agrformet.2015.09.015.

50. Li Z-G, Cheng H, Gu T-Y (2019) Research on dynamic relationship between natural gas consumption and economic growth in China. Structural Change and Economic Dynamics 49: 334-339, https://doi.org/10.1016/j.strueco.2018.11.006. 51. Zhang C, Wang H (2020) Swing vibration control of suspended structures using the Active Rotary Inertia Driver system: Theoretical modeling and experimental verification. Structural Control and Health Monitoring 27: e2543, https://doi.org/10.1002/stc. 2543 .

52. Zhang C, Abedini M, Mehrmashhadi J (2020) Development of pressure-impulse models and residual capacity assessment of RC columns using high fidelity Arbitrary Lagrangian-Eulerian simulation. Engineering Structures 224: 111219, https://doi.org/10.1016/j.engstruct.2020.111219.

53. Yue H, Wang H, Chen H, Cai K, Jin Y (2020) Automatic detection of feather defects using Lie group and fuzzy Fisher criterion for shuttlecock production. Mechanical Systems and Signal Processing 141: 106690, https://doi.org/10.1016/j.ymssp.2020.106690.

54. Gholipour G, Zhang C, Mousavi AA (2020) Numerical analysis of axially loaded RC columns subjected to the combination of impact and blast loads. Engineering Structures 219: 110924, https://doi.org/10.1016/j.engstruct.2020.110924.

55. Abedini M, Zhang C (2020) Performance Assessment of Concrete and Steel Material Models in LS-DYNA for Enhanced Numerical Simulation, A State of the Art Review. Archives of Computational Methods in Engineering 10.1007/s11831-020-09483-5.

56. Mou B, Zhao F, Qiao Q, Wang L, Li H, He B, Hao Z (2019) Flexural behavior of beam to column joints with or without an overlying concrete slab. Engineering Structures 199: 109616, https://doi.org/10.1016/j.engstruct.2019.109616. 57. Liu J, Wu C, Wu G, Wang X (2015) A novel differential search algorithm and applications for structure design. Applied Mathematics and Computation 268: 246-269,

58. Abedini M, Mutalib AA, Zhang C, Mehrmashhadi J, Raman SN, Alipour R, Momeni T, Mussa MH (2020) Large deflection behavior effect in reinforced concrete columns exposed to extreme dynamic loads. Frontiers of Structural and Civil Engineering 14: 532-553, 10.1007/s11709-020-0604-9.

59. Sun Y, Wang J, Wu J, Shi W, Ji D, Wang X, Zhao X (2020) Constraints hindering the development of high-rise modular buildings. Applied Sciences 10: 7159, https://doi.org/10.3390/app10207159.

60. Mou B, Li X, Bai Y, Wang L (2019) Shear behavior of panel zones in steel beam-to-column connections with unequal depth of outer annular stiffener. Journal of Structural Engineering 145: 04018247, 10.1061/(ASCE)ST.1943541X.0002256. 
61. Wang J, Huang Y, Wang T, Zhang C, Liu Yh (2020) Fuzzy finite-time stable compensation control for a building structural vibration system with actuator failures. Applied Soft Computing 93: 106372, https://doi.org/10.1016/j.asoc.2020.106372.

62. Xu M, Li C, Zhang S, Callet PL (2020) State-of-the-Art in $360^{\circ}$ Video/Image Processing: Perception, Assessment and Compression. IEEE Journal of Selected Topics in Signal Processing 14: 5-26, 10.1109/JSTSP.2020.2966864.

63. Chao M, Kai C, Zhiwei Z (2020) Research on tobacco foreign body detection device based on machine vision. Transactions of the Institute of Measurement and Control 42: 2857-2871, 10.1177/0142331220929816.

64. Zenggang X, Zhiwen T, Xiaowen C, Xue-min Z, Kaibin Z, Conghuan Y (2019) Research on Image Retrieval Algorithm Based on Combination of Color and Shape Features. Journal of Signal Processing Systems 1-8, https://doi.org/10.1007/s11265-019-01508-y.

65. Xu S, Wang J, Shou W, Ngo T, Sadick A-M, Wang X (2020) Computer Vision Techniques in Construction: A Critical Review. Archives of Computational Methods in Engineering 10.1007/s11831-020-09504-3.

66. Zhu G, Wang S, Sun L, Ge W, Zhang X (2020) Output Feedback Adaptive Dynamic Surface Sliding-Mode Control for Quadrotor UAVs with Tracking Error Constraints. Complexity 2020: 8537198, 10.1155/2020/8537198.

67. Xiong Q, Zhang X, Wang W-F, Gu Y (2020) A Parallel Algorithm Framework for Feature Extraction of EEG Signals on MPI. Computational and Mathematical Methods in Medicine 2020: 9812019, 10.1155/2020/9812019.

68. Zhang J, Liu B (2019) A review on the recent developments of sequence-based protein feature extraction methods. Current Bioinformatics 14: 190-199,

69. Zhang X, Fan M, Wang D, Zhou P, Tao D (2020) Top-k Feature Selection Framework Using Robust 0-1 Integer Programming. IEEE Transactions on Neural Networks and Learning Systems 1-15, 10.1109/TNNLS.2020.3009209.

70. Zhao X, Li D, Yang B, Chen H, Yang X, Yu C, Liu S (2015) A two-stage feature selection method with its application. Computers \& Electrical Engineering 47: 114-125,

71. Wang S-J, Chen H-L, Yan W-J, Chen Y-H, Fu X (2014) Face recognition and micro-expression recognition based on discriminant tensor subspace analysis plus extreme learning machine. Neural processing letters 39: 25-43,

72. Xia J, Chen H, Li Q, Zhou M, Chen L, Cai Z, Fang Y, Zhou H (2017) Ultrasound-based differentiation of malignant and benign thyroid Nodules: An extreme learning machine approach. Computer methods and programs in biomedicine 147: 37-49,

73. Zhang X, Jiang R, Wang T, Wang J (2020) Recursive Neural Network for Video Deblurring. IEEE Transactions on Circuits and Systems for Video Technology 1-1, 10.1109/TCSVT.2020.3035722.

74. Zhang X, Wang T, Wang J, Tang G, Zhao L (2020) Pyramid Channel-based Feature Attention Network for image dehazing. Computer Vision and Image Understanding 197-198: 103003, https://doi.org/10.1016/j.cviu.2020.103003.

75. Chen Z, Wang J, Ma K, Huang X, Wang T (2020) Fuzzy adaptive two-bits-triggered control for nonlinear uncertain system with input saturation and output constraint. International Journal of Adaptive Control and Signal Processing 34: 543-559, https://doi.org/10.1002/acs.3098.

76. Huang Z, Zheng H, Guo L, Mo D (2020) Influence of the Position of Artificial Boundary on Computation Accuracy of Conjugated Infinite Element for a Finite Length Cylindrical Shell. Acoustics Australia 48: 287-294, 10.1007/s40857020-00175-5.

77. Tian P, Lu H, Feng W, Guan Y, Xue Y (2020) Large decrease in streamflow and sediment load of Qinghai-Tibetan Plateau driven by future climate change: A case study in Lhasa River Basin. CATENA 187: 104340, https://doi.org/10.1016/j.catena.2019.104340.

78. Wang X, Liu Y, Choo K (2020) Fault tolerant, ulti-subset aggregation scheme for smart grid. IEEE Transactions on Industrial Informatics

79. Wu C, Wu P, Wang J, Jiang R, Chen M, Wang X (2021) Ontological knowledge base for concrete bridge rehabilitation project management. Automation in Construction 121: 103428, https://doi.org/10.1016/j.autcon.2020.103428.

80. Hu L, Hong G, Ma J, Wang X, Chen H (2015) An efficient machine learning approach for diagnosis of paraquatpoisoned patients. Computers in Biology and Medicine 59: 116-124,

81. Li C, Hou L, Sharma BY, Li H, Chen C, Li Y, Zhao X, Huang H, Cai Z, Chen H (2018) Developing a new intelligent system for the diagnosis of tuberculous pleural effusion. Computer methods and programs in biomedicine 153: 211-225, 82. Zhao X, Zhang X, Cai Z, Tian X, Wang X, Huang Y, Chen H, Hu L (2019) Chaos enhanced grey wolf optimization wrapped ELM for diagnosis of paraquat-poisoned patients. Computational Biology and Chemistry 78: 481-490, 10.1016/j.compbiolchem.2018.11.017.

83. Jalali A, Behrouzi MK, Salari N, Bazrafshan M-R, Rahmati M (2019) The effectiveness of group spiritual intervention on self-esteem and happiness among men undergoing methadone maintenance treatment. Current Drug Research Reviews Formerly: Current Drug Abuse Reviews 11: 67-72,

84. Salari N, Shohaimi S, Najafi F, Nallappan M, Karishnarajah I (2013) Application of pattern recognition tools for classifying acute coronary syndrome: an integrated medical modeling. Theoretical Biology and Medical Modelling 10: $57,10.1186 / 1742-4682-10-57$.

85. Chen H-L, Wang G, Ma C, Cai Z-N, Liu W-B, Wang S-J (2016) An efficient hybrid kernel extreme learning machine approach for early diagnosis of Parkinson's disease. Neurocomputing 184: 131-144,

86. Mohammadi M, Raiegani AAV, Jalali R, Ghobadi A, Salari N (2019) The prevalence of retinopathy among type 2 diabetic patients in Iran: A systematic review and meta-analysis. Reviews in Endocrine and Metabolic Disorders 20: 7988 , 
87. Liu D, Wang S, Huang D, Deng G, Zeng F, Chen H (2016) Medical image classification using spatial adjacent histogram based on adaptive local binary patterns. Computers in Biology and Medicine 72: 185-200,

88. Chen H, Heidari AA, Chen H, Wang M, Pan Z, Gandomi AH (2020) Multi-population differential evolution-assisted Harris hawks optimization: Framework and case studies. Future Generation Computer Systems 111: 175-198, https://doi.org/10.1016/j.future.2020.04.008.

89. Qu S, Han Y, Wu Z, Raza H (2020) Consensus Modeling with Asymmetric Cost Based on Data-Driven Robust Optimization. Group Decision and Negotiation 10.1007/s10726-020-09707-w.

90. Wang M, Chen H (2020) Chaotic multi-swarm whale optimizer boosted support vector machine for medical diagnosis. Applied Soft Computing Journal 88: 10.1016/j.asoc.2019.105946.

91. Cao Y, Li Y, Zhang G, Jermsittiparsert K, Nasseri M (2020) An efficient terminal voltage control for PEMFC based on an improved version of whale optimization algorithm. Energy Reports 6: 530-542, https://doi.org/10.1016/j.egyr.2020.02.035.

92. Zhang Y, Liu R, Wang X, Chen H, Li C (2020) Boosted binary Harris hawks optimizer and feature selection. Engineering with Computers https://doi.org/10.1007/s00366-020-01028-5.

93. Mi C, Cao L, Zhang Z, Feng Y, Yao L, Wu Y (2020) A port container code recognition algorithm under natural conditions. Journal of Coastal Research 103: 822-829, https://doi.org/10.2112/SI103-170.1.

94. Cao B, Dong W, Lv Z, Gu Y, Singh S, Kumar P (2020) Hybrid Microgrid Many-Objective Sizing Optimization With Fuzzy Decision. IEEE Transactions on Fuzzy Systems 28: 2702-2710,

95. Shen L, Chen H, Yu Z, Kang W, Zhang B, Li H, Yang B, Liu D (2016) Evolving support vector machines using fruit fly optimization for medical data classification. Knowledge-Based Systems 96: 61-75,

96. Wang M, Chen H, Yang B, Zhao X, Hu L, Cai Z, Huang H, Tong C (2017) Toward an optimal kernel extreme learning machine using a chaotic moth-flame optimization strategy with applications in medical diagnoses. Neurocomputing 267: 69-84,

97. Xu Y, Chen H, Luo J, Zhang Q, Jiao S, Zhang X (2019) Enhanced Moth-flame optimizer with mutation strategy for global optimization. Information Sciences 492: 181-203,

98. Xu X, Chen H-L (2014) Adaptive computational chemotaxis based on field in bacterial foraging optimization. Soft Computing 18: 797-807,

99. Zhao X, Li D, Yang B, Ma C, Zhu Y, Chen H (2014) Feature selection based on improved ant colony optimization for online detection of foreign fiber in cotton. Applied Soft Computing 24: 585-596,

100. Moayedi H, Tien Bui D, Gör M, Pradhan B, Jaafari A (2019) The Feasibility of Three Prediction Techniques of the Artificial Neural Network, Adaptive Neuro-Fuzzy Inference System, and Hybrid Particle Swarm Optimization for Assessing the Safety Factor of Cohesive Slopes. ISPRS International Journal of Geo-Information 8: 391,

101. Xi W, Li G, Moayedi H, Nguyen. H (2019) A particle-based optimization of artificial neural network for earthquakeinduced landslide assessment in Ludian county, China Geomatics, Natural Hazards and Risk 10: 1750-1771,

102. Zhou G, Moayedi H, Bahiraei M, Lyu Z (2020) Employing artificial bee colony and particle swarm techniques for optimizing a neural network in prediction of heating and cooling loads of residential buildings. Journal of Cleaner Production 254: 10.1016/j.jclepro.2020.120082.

103. Cao B, Fan S, Zhao J, Yang P, Muhammad K, Tanveer M (2020) Quantum-enhanced multiobjective large-scale optimization via parallelism. Swarm and Evolutionary Computation 57: 100697, https://doi.org/10.1016/j.swevo.2020.100697.

104. Veiskarami M, Habibagahi G (2013) Foundations bearing capacity subjected to seepage by the kinematic approach of the limit analysis. Frontiers of Structural and Civil Engineering 7: 446-455,

105. Merifield RS, Lyamin AV, Sloan S (2006) Limit analysis solutions for the bearing capacity of rock masses using the generalised Hoek-Brown criterion. International Journal of Rock Mechanics and Mining Sciences 43: 920-937,

106. Salari-Rad H, Mohitazar M, Dizadji MR (2013) Distinct element simulation of ultimate bearing capacity in jointed rock foundations. Arabian Journal of Geosciences 6: 4427-4434,

107. Khorrami R, Derakhshani A, Moayedi H (2020) New explicit formulation for shallow foundations' ultimate bearing capacity rested on granular soil using M5'model tree. Measurement 108032,

108. Khorrami R, Derakhshani A (2019) Estimation of ultimate bearing capacity of shallow foundations resting on cohesionless soils using a new hybrid M5'-GP model. Geomechanics and Engineering 19: 127-139,

109. Sethy B, Patra C, Sivakugan N, Das B (2017) Application of ANN and ANFIS for predicting the ultimate bearing capacity of eccentrically loaded rectangular foundations. International Journal of Geosynthetics and Ground Engineering 3: 35 ,

110. Dutta RK, Khatri VN, Gnananandarao T (2019) Soft Computing Based Prediction of Ultimate Bearing Capacity of Footings Resting on Rock Masses. International Journal of Geological and Geotechnical Engineering 5: 1-14,

111. Moayedi H, Hayati S (2018) Modelling and optimization of ultimate bearing capacity of strip footing near a slope by soft computing methods. Applied Soft Computing 66: 208-219,

112. Acharyya R, Dey A (2019) Assessment of bearing capacity for strip footing located near sloping surface considering ANN model. Neural Computing and Applications 31: 8087-8100,

113. Aouadj A, Bouafia A (2020) CPT-based method using hybrid artificial neural network and mathematical model to predict the load-settlement behaviour of shallow foundations. Geomechanics and Geoengineering 1-13,

114. Acharyya R, Dey A, Kumar B (2018) Finite element and ANN-based prediction of bearing capacity of square footing resting on the crest of $c-\varphi$ soil slope. International Journal of Geotechnical Engineering 
115. Bagińska M, Srokosz PE (2019) The optimal ANN Model for predicting bearing capacity of shallow foundations trained on scarce data. KSCE Journal of Civil Engineering 23: 130-137,

116. Dutta RK, Rani R, Rao TG (2018) Prediction of ultimate bearing capacity of skirted footing resting on sand using artificial neural networks. Journal of Soft Computing in Civil Engineering 2: 34-46,

117. Zhang C-W, Ou J-P, Zhang J-Q (2006) Parameter optimization and analysis of a vehicle suspension system controlled by magnetorheological fluid dampers. Structural Control and Health Monitoring 13: 885-896, https://doi.org/10.1002/stc.63.

118. Chen Y, He L, Guan Y, Lu H, Li J (2017) Life cycle assessment of greenhouse gas emissions and water-energy optimization for shale gas supply chain planning based on multi-level approach: Case study in Barnett, Marcellus, Fayetteville, and Haynesville shales. Energy Conversion and Management 134: 382-398, https://doi.org/10.1016/j.enconman.2016.12.019.

119. Deng Y, Zhang T, Sharma BK, Nie H (2019) Optimization and mechanism studies on cell disruption and phosphorus recovery from microalgae with magnesium modified hydrochar in assisted hydrothermal system. Science of The Total Environment 646: 1140-1154, https://doi.org/10.1016/j.scitotenv.2018.07.369.

120. Liu E, Lv L, Yi Y, Xie P (2019) Research on the Steady Operation Optimization Model of Natural Gas Pipeline Considering the Combined Operation of Air Coolers and Compressors. IEEE Access 7: 83251-83265, 10.1109/ACCESS.2019.2924515.

121. Sun G, Yang B, Yang Z, Xu G (2019) An adaptive differential evolution with combined strategy for global numerical optimization. Soft Computing 1-20, https://doi.org/10.1007/s00500-019-03934-3.

122. Cao B, Wang X, Zhang W, Song H, Lv Z (2020) A Many-Objective Optimization Model of Industrial Internet of Things Based on Private Blockchain. IEEE Network 34: 78-83,

123. Cao B, Zhao J, Gu Y, Fan S, Yang P (2020) Security-Aware Industrial Wireless Sensor Network Deployment Optimization. IEEE Transactions on Industrial Informatics 16: 5309-5316, 10.1109/TII.2019.2961340.

124. Cao B, Zhao J, Gu Y, Ling Y, Ma X (2020) Applying graph-based differential grouping for multiobjective largescale optimization. Swarm and Evolutionary Computation 53: 100626, https://doi.org/10.1016/j.swevo.2019.100626.

125. Cao B, Zhao J, Yang P, Gu Y, Muhammad K, Rodrigues JJPC, Albuquerque VHCd (2020) Multiobjective 3-D Topology Optimization of Next-Generation Wireless Data Center Network. IEEE Transactions on Industrial Informatics 16: 3597-3605, 10.1109/TII.2019.2952565.

126. Fu X, Pace P, Aloi G, Yang L, Fortino G (2020) Topology Optimization Against Cascading Failures on Wireless Sensor Networks Using a Memetic Algorithm. Computer Networks 107327,

127. Zhang X, Wang D, Zhou Z, Ma Y (2019) Robust Low-Rank Tensor Recovery with Rectification and Alignment. IEEE Transactions on Pattern Analysis and Machine Intelligence 1-1, 10.1109/TPAMI.2019.2929043.

128. Hamrouni A, Sbartai B, Dias D (2018) Probabilistic analysis of ultimate seismic bearing capacity of strip foundations. Journal of Rock Mechanics and Geotechnical Engineering 10: 717-724,

129. Saha A, Saha AK, Ghosh S (2018) Pseudodynamic bearing capacity analysis of shallow strip footing using the advanced optimization technique "hybrid symbiosis organisms search algorithm" with numerical validation. Advances in Civil Engineering 2018:

130. Jin L, Zhang H, Feng Q (2020) Ultimate bearing capacity of strip footing on sands under inclined loading based on improved radial movement optimization. Engineering Optimization 1-23,

131. Kashani AR, Gandomi M, Camp CV, Gandomi AH (2019) Optimum design of shallow foundation using evolutionary algorithms. Soft Computing 1-25,

132. Gandomi AH, Kashani AR (2017) Construction cost minimization of shallow foundation using recent swarm intelligence techniques. IEEE Transactions on Industrial Informatics 14: 1099-1106,

133. Moayedi H, Kalantar B, Dounis A, Tien Bui D, Foong LK (2019) Development of Two Novel Hybrid Prediction Models Estimating Ultimate Bearing Capacity of the Shallow Circular Footing. Applied Sciences 9: 4594,

134. Moayedi H, Bui DT, Ngo T, Thao P (2019) Neural Computing Improvement Using Four Metaheuristic Optimizers in Bearing Capacity Analysis of Footings Settled on Two-Layer Soils. Applied Sciences 9: 5264,

135. Pakdel P, Jamshidi Chenari R, Veiskarami M (2019) An estimate of the bearing capacity of shallow foundations on anisotropic soil by limit equilibrium and soft computing technique. Geomechanics and Geoengineering 14: 202-217,

136. Andrab SG, Hekmat A, Yusop ZB (2017) A review: evolutionary computations (GA and PSO) in geotechnical engineering. Computational Water, Energy, and Environmental Engineering 6: 154-179,

137. Foong LK, Moayedi H, Lyu Z (2020) Computational modification of neural systems using a novel stochastic search scheme, namely evaporation rate-based water cycle algorithm: an application in geotechnical issues. Engineering with Computers 1-12,

138. Nasir M, Sadollah A, Choi YH, Kim JH (2020) A comprehensive review on water cycle algorithm and its applications. Neural Computing and Applications 1-56,

139. Eskandar H, Sadollah A, Bahreininejad A, Hamdi M (2012) Water cycle algorithm-A novel metaheuristic optimization method for solving constrained engineering optimization problems. Computers \& Structures 110: 151-166, 140. David S (1993) The Water Cycle (John Yates, Illus). Thomson Learning, New York

141. Heidari AA, Abbaspour RA, Jordehi AR (2017) An efficient chaotic water cycle algorithm for optimization tasks. Neural Computing and Applications 28: 57-85,

142. Luo Q, Wen C, Qiao S, Zhou Y (2016) Dual-system water cycle algorithm for constrained engineering optimization problems. International Conference on Intelligent Computing, 
143. Abedinpourshotorban H, Shamsuddin SM, Beheshti Z, Jawawi DN (2016) Electromagnetic field optimization: A physics-inspired metaheuristic optimization algorithm. Swarm and Evolutionary Computation 26: 8-22,

144. Talebi B, Dehkordi MN (2018) Sensitive association rules hiding using electromagnetic field optimization algorithm. Expert Systems with Applications 114: 155-172,

145. Bouchekara H, Zellagui M, Abido MA (2017) Optimal coordination of directional overcurrent relays using a modified electromagnetic field optimization algorithm. Applied Soft Computing 54: 267-283,

146. Song S, Jia H, Ma J (2019) A chaotic electromagnetic field optimization algorithm based on fuzzy entropy for multilevel thresholding color image segmentation. Entropy 21: 398,

147. Duan Q, Gupta VK, Sorooshian S (1993) Shuffled complex evolution approach for effective and efficient global minimization. Journal of optimization theory and applications 76: 501-521,

148. Nelder JA, Mead R (1965) A simplex method for function minimization. The computer journal 7: 308-313,

149. Liong S-Y, Atiquzzaman M (2004) Optimal design of water distribution network using shuffled complex evolution. Journal of The Institution of Engineers, Singapore 44: 93-107,

150. Majeed K, Qyyum MA, Nawaz A, Ahmad A, Naqvi M, He T, Lee M (2020) Shuffled Complex Evolution-Based Performance Enhancement and Analysis of Cascade Liquefaction Process for Large-Scale LNG Production. Energies 13: 2511 ,

151. Bayat P, Afrakhte H (2020) A purpose-oriented shuffled complex evolution optimization algorithm for energy management of multi-microgrid systems considering outage duration uncertainty. Journal of Intelligent \& Fuzzy Systems $1-18$,

152. Nguyen H, Mehrabi M, Kalantar B, Moayedi H, Abdullahi MaM (2019) Potential of hybrid evolutionary approaches for assessment of geo-hazard landslide susceptibility mapping. Geomatics, Natural Hazards and Risk 10: 1667-1693, 153. Seyedashraf O, Mehrabi M, Akhtari AA (2018) Novel approach for dam break flow modeling using computational intelligence. Journal of Hydrology 559: 1028-1038, 
Figures

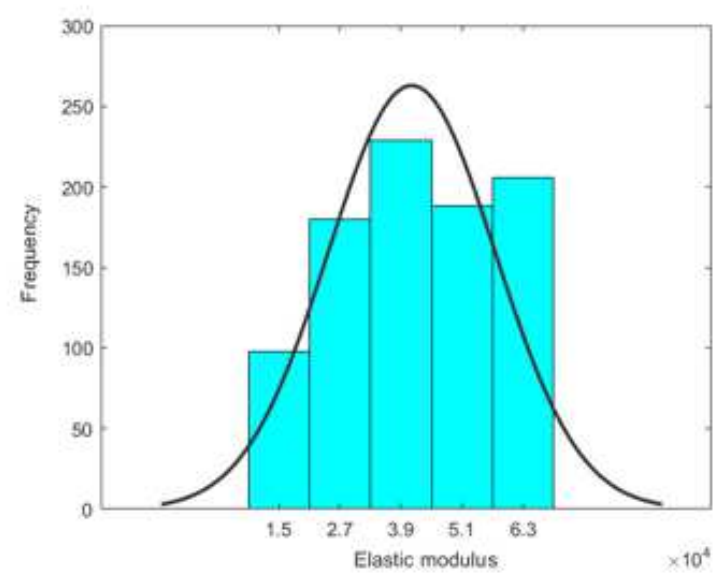

(c)

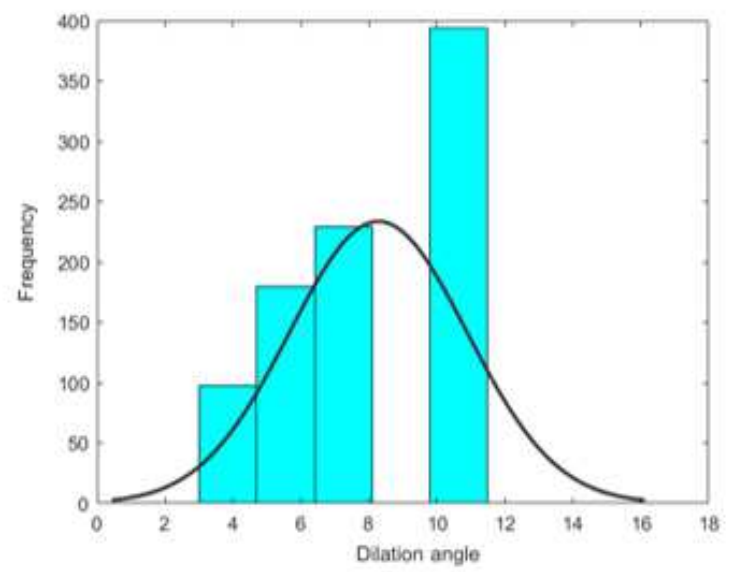

(e)

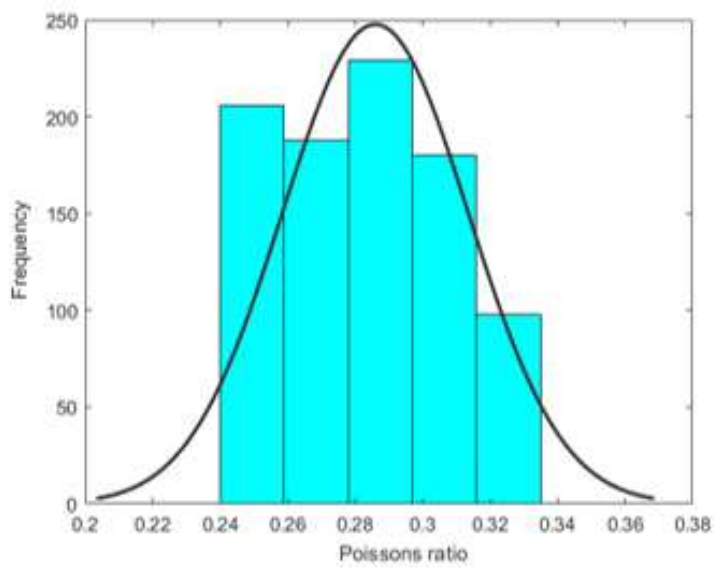

(g)

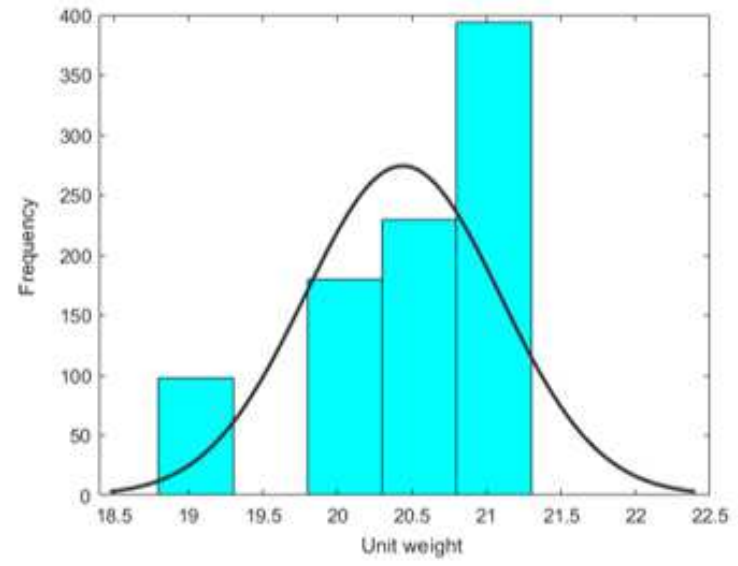

(d)

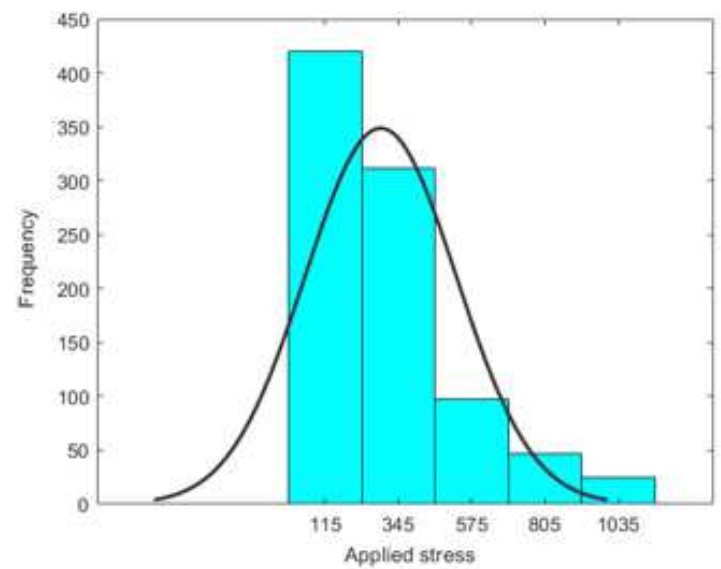

(f)

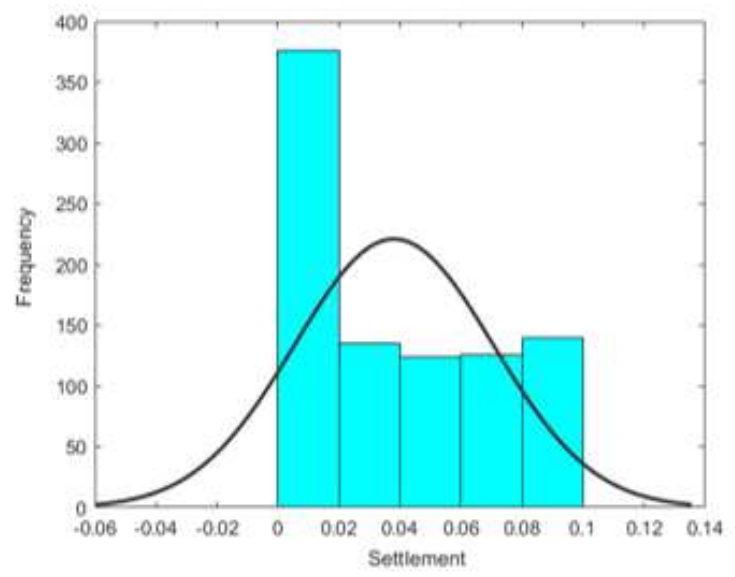

(h)

\section{Figure 1}

Histogram diagram of the parameters of the prepared dataset. 


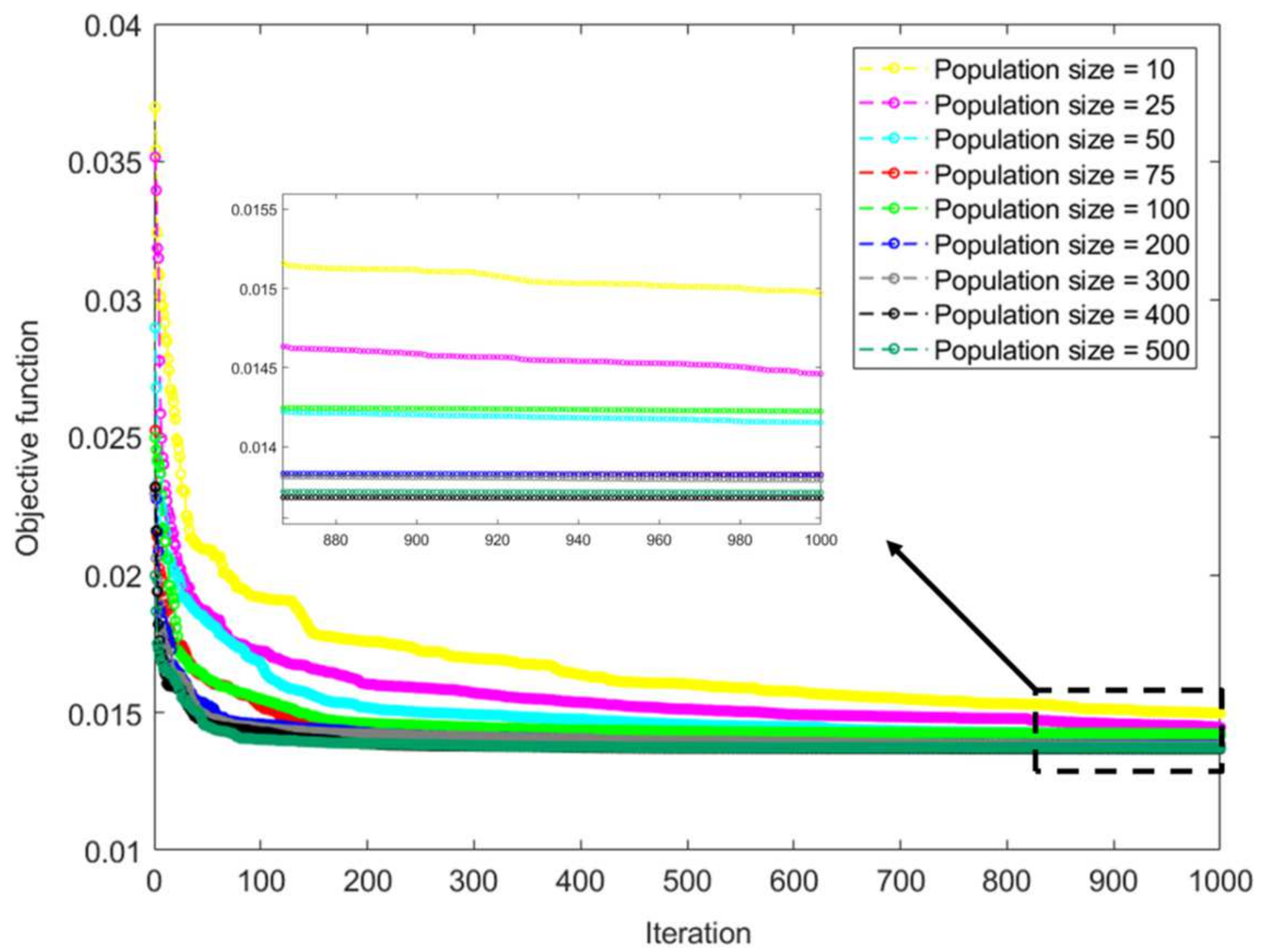

Figure 2

The sensitivity of the WCA performance to the population size. 


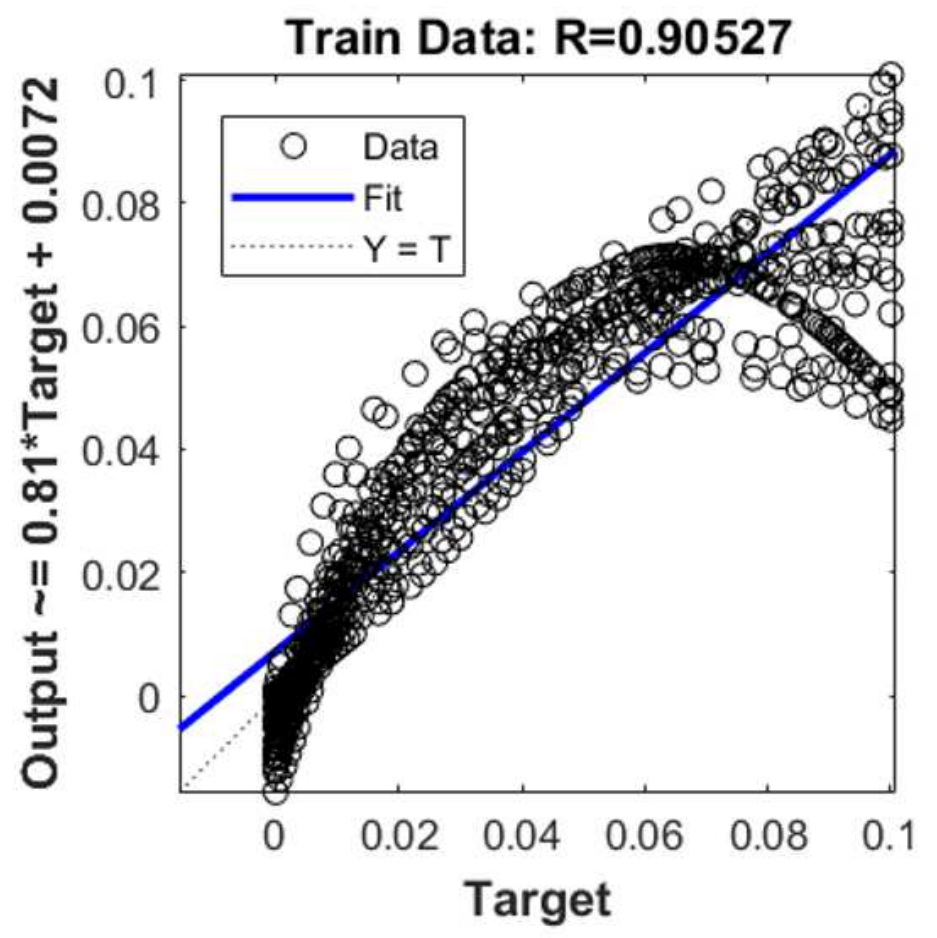

(a)

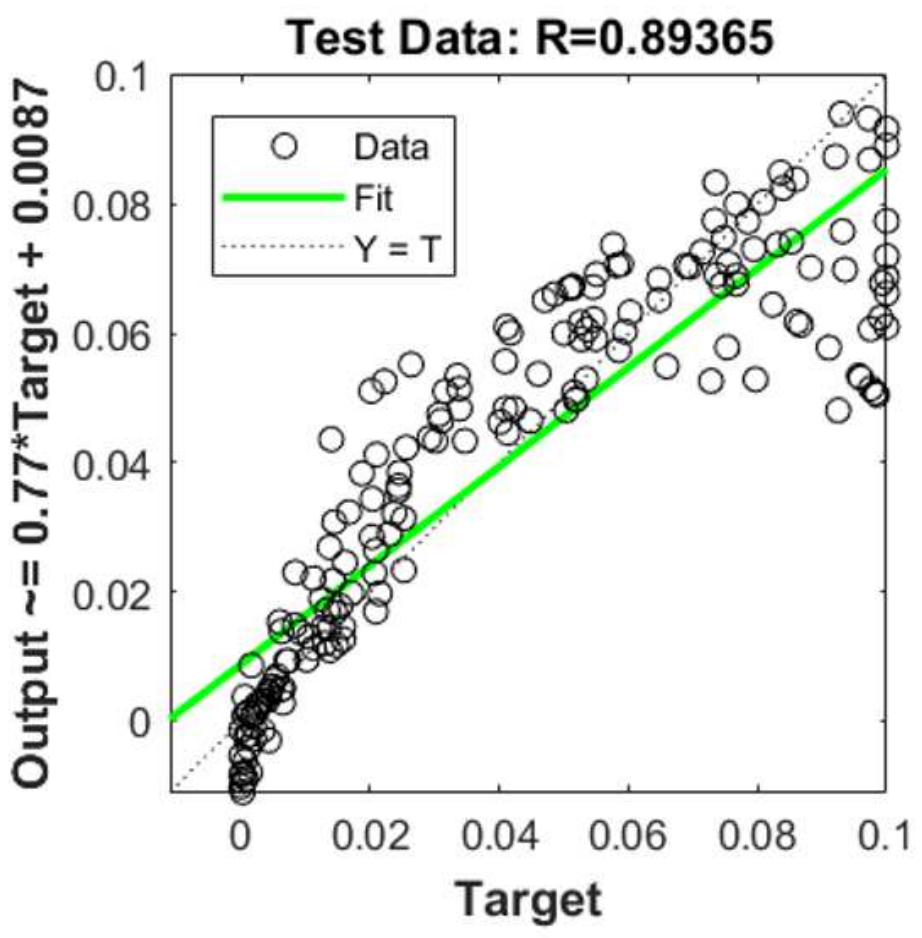

(b)

Figure 3

The regression charts of the (a) training and (b) testing results for the WCA-MLP.

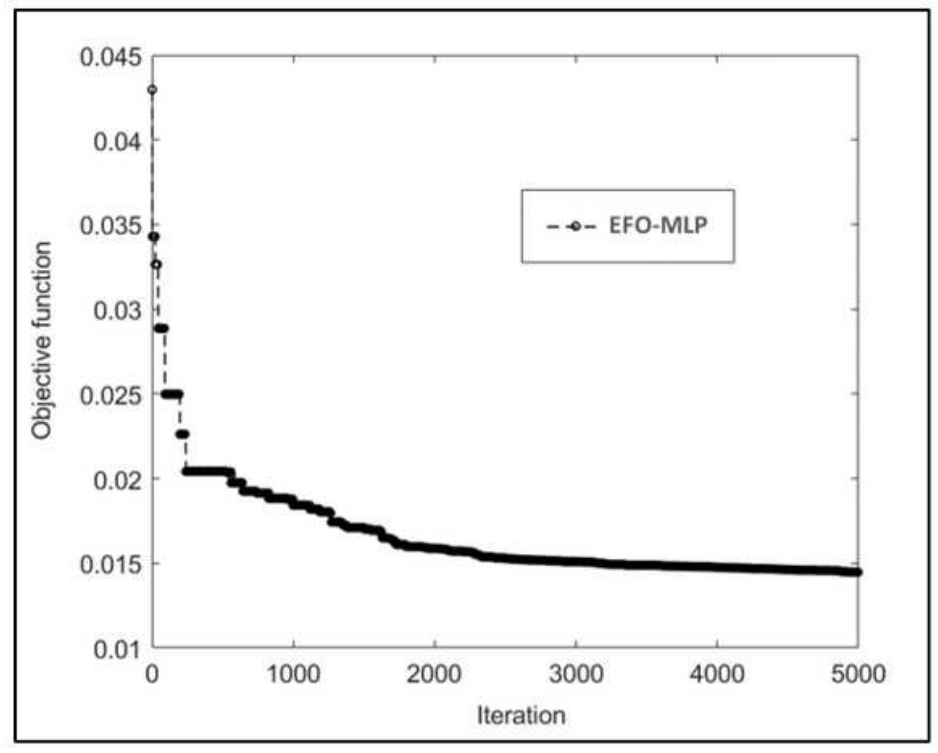

(a)

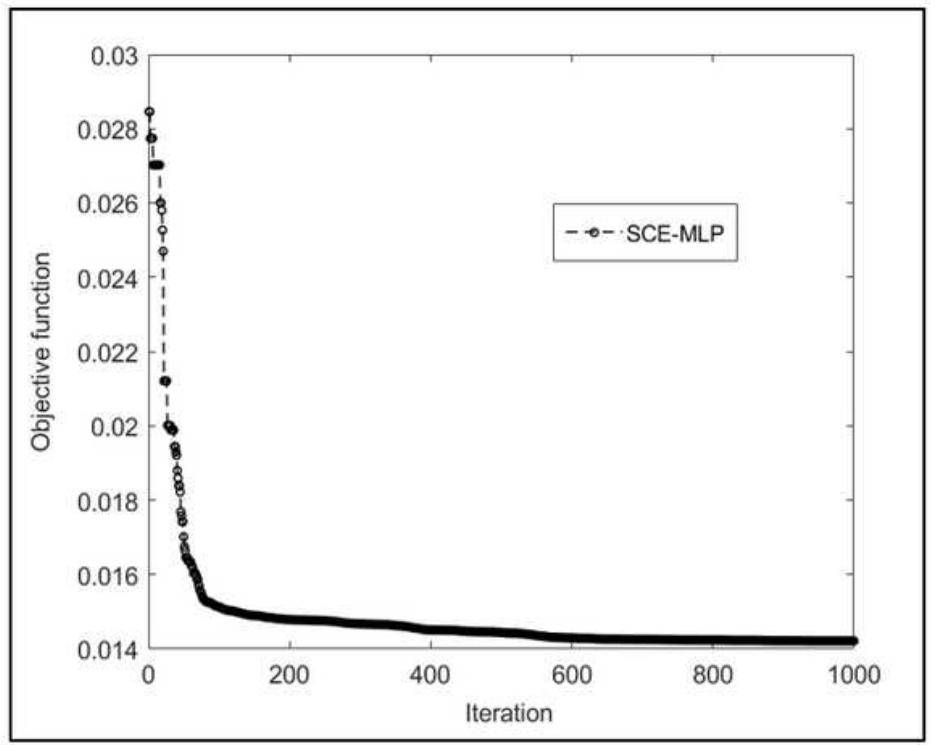

(b)

Figure 4

The convergence curves of the benchmark methods. 


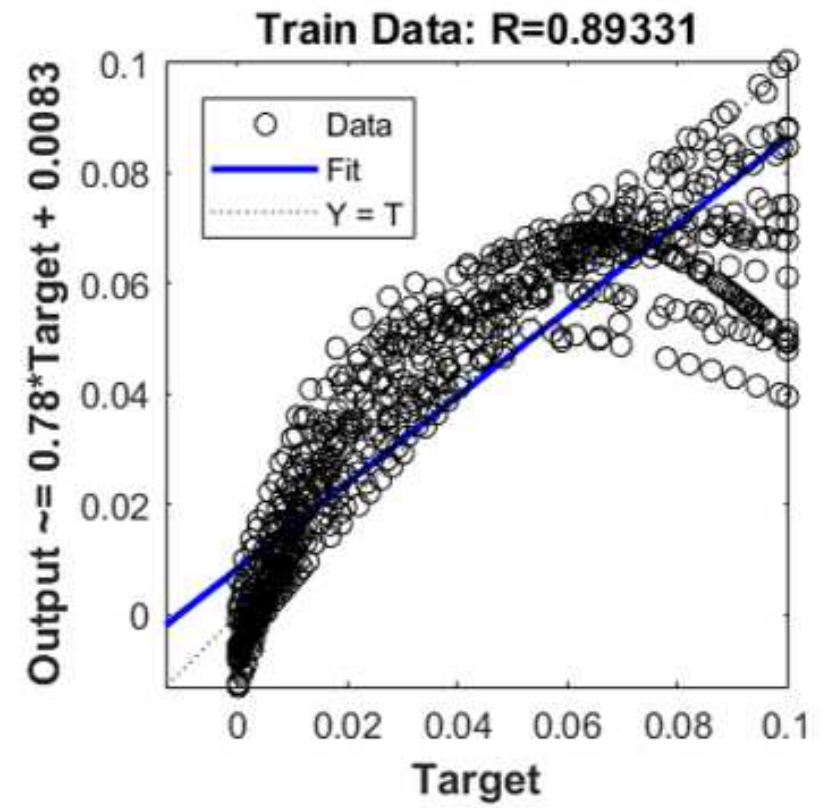

(a)

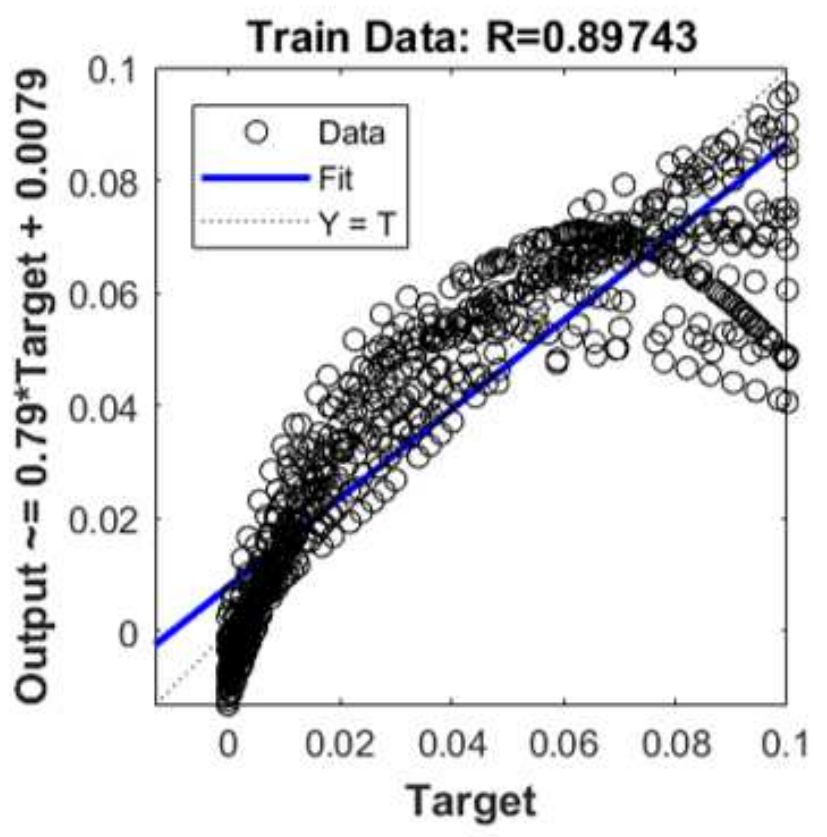

(c)

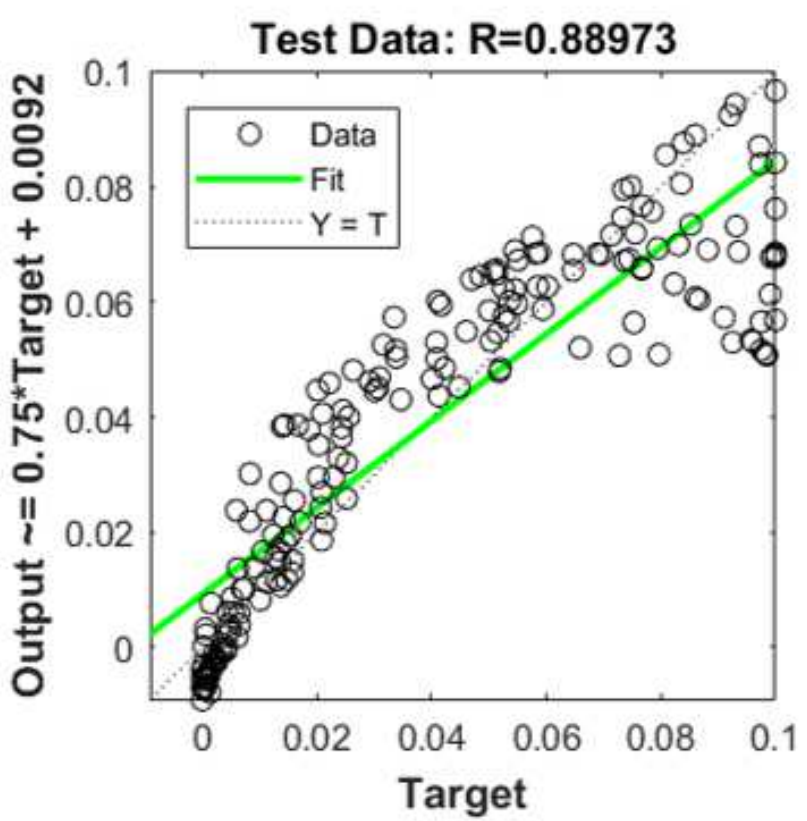

(b)

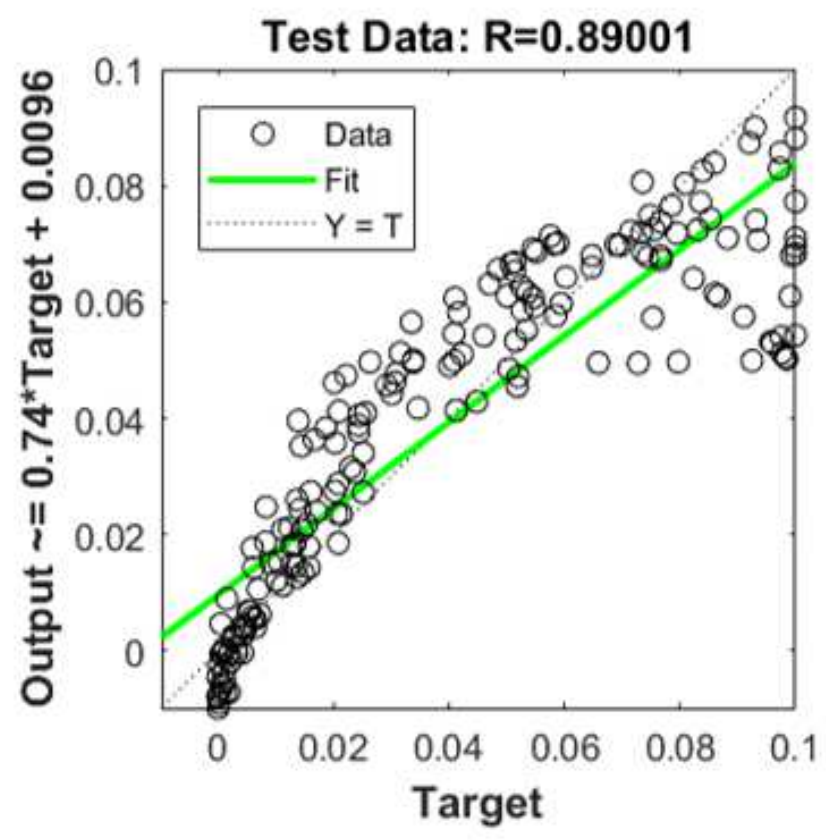

(d)

\section{Figure 5}

The regression charts of the training and testing results for the ( $a$ and b) EFO-MLP and (c and d) SCEMLP. 


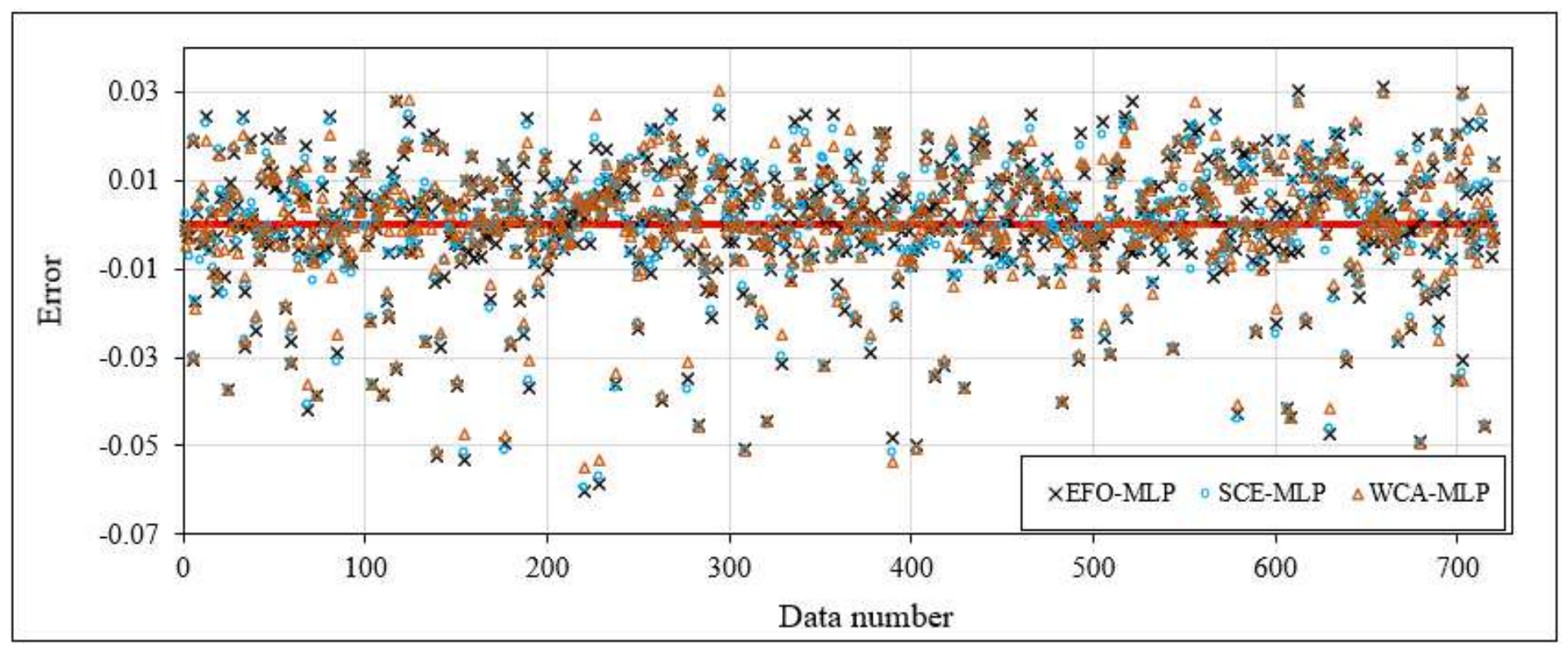

(a)

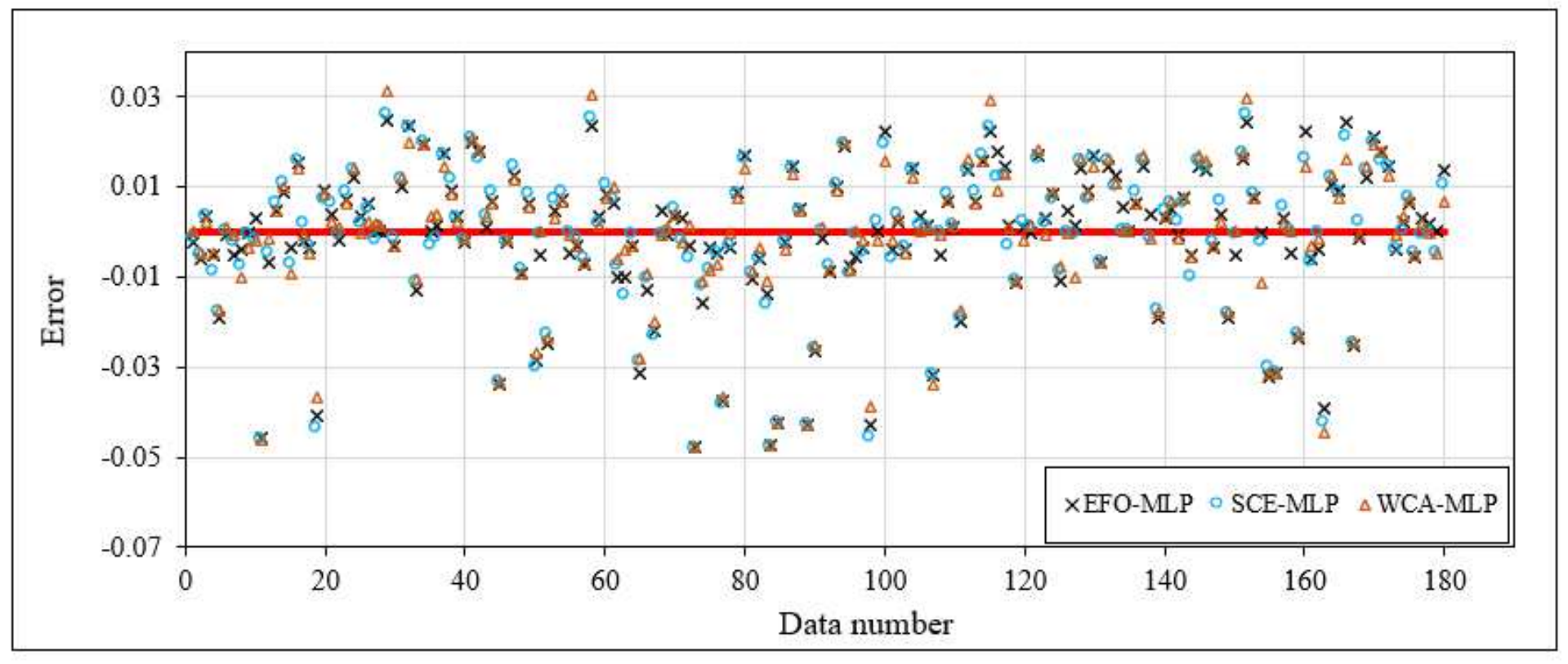

(b)

Figure 6

A graphical comparison of the (a) training and (b) testing errors for all used models. 


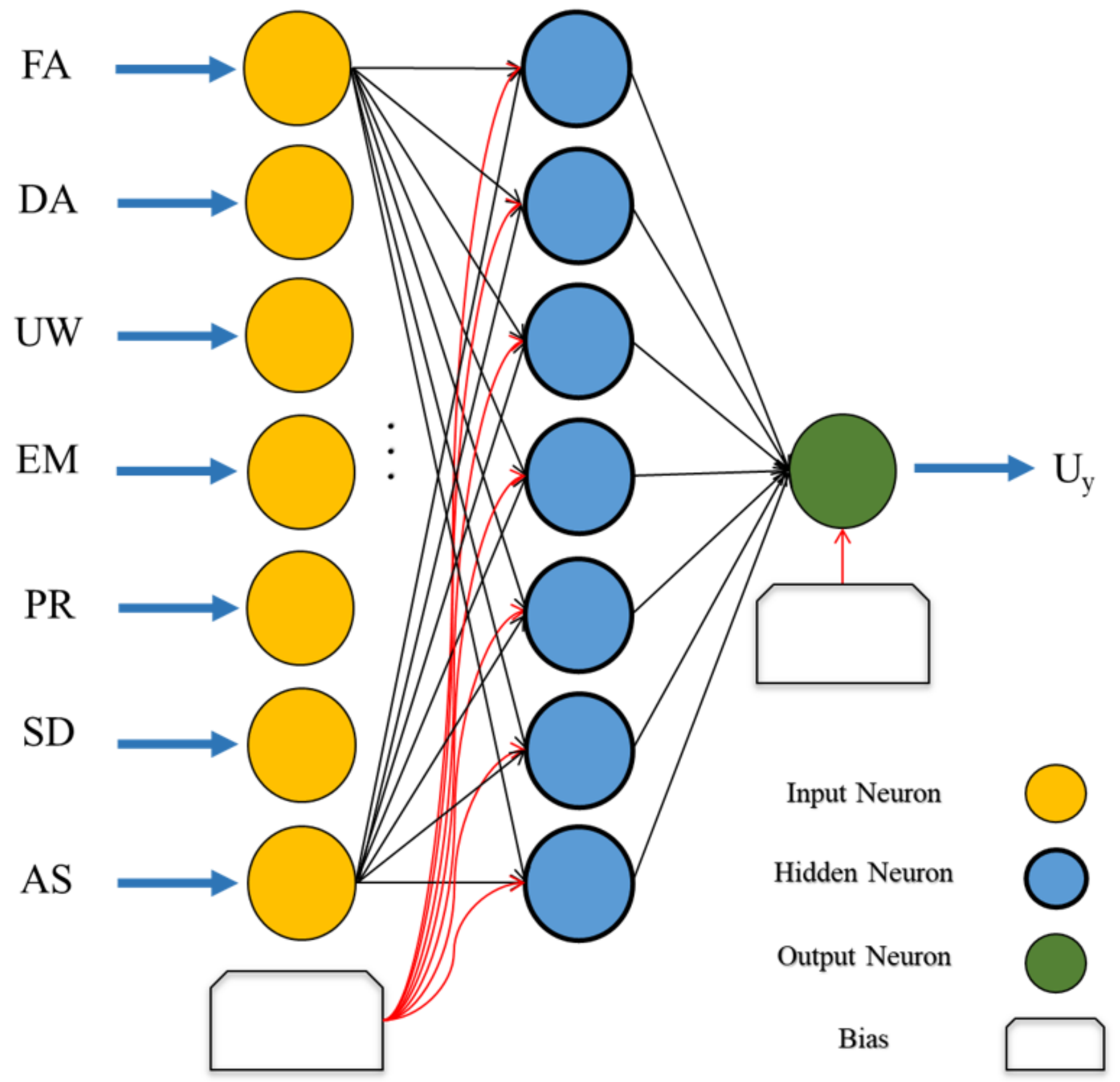

Figure 7

The neural structure of the used predictive model. 